\title{
O USO DO GIS PARA ENTENDER O SISTEMA DE TROCAS NO EGITO ANTIGO E NA NÚBIA : MAPAS DE CIRCULAÇÃO, UMA NOVAABORDAGEM PARAAS SUPERFÍCIES DE CUSTO
}

\author{
José Roberto Pellini*
}

\begin{abstract}
PELLINI, J.R. O uso do GIS para entender o sistema de trocas no Egito Antigo e na Núbia: mapas de circulação, uma nova abordagem para as superfícies de custo. Rev. do Museu de Arqueologia e Etnologia, São Paulo, 15-16: 209-245, 2005-2006.
\end{abstract}

RESUMO: Nos últimos anos, análises de custo de superfície têm sido utilizadas na arqueologia para modelar os antigos sistemas de troca. O principal problema relacionado com este tipo de análise é que em geral estes modelos obedecem a uma estrutura interpretativa derivada da moderna teoria econômica, o que reduz a análise de custo a uma questão de racionalização das distâncias. Como a movimentação de pessoas bem como circulação de bens dentro da paisagem é condicionada tanto por aspectos físicos quanto simbólicos, propusemos, em nosso doutorado, mapas de custo de superfície que incorporam não somente fatores físicos mas também fatores sócioculturais. A estes mapas de custo de superfície físico-culturais, agregamos dados sobre a distribuição de objetos arqueológicos dentro da área de estudo. O resultado final é o que denominamos como mapas de circulação, onde cada tipo diferenciado de movimento pode, dependendo da área a ser estudada, evidenciar a presença de diferentes sistemas e esferas de troca.

UNITERMOS: Egito Antigo - GIS - Sistemas de troca - Comércio.

\section{Introdução}

Sistemas de Informação Geográfica têm revolucionado nos últimos anos a maneira com a qual disciplinas como a geografia, ecologia e arqueologia manuseiam e interpretam grupos de dados espacialmente referenciados. Estes sistemas de informação fornecem um meio de manipular observações complexas e multi-variadas com muita flexibilidade. Uma das maiores vantagens do GIS é

(*) Doutor em arqueologia pelo Museu de Arqueologia e Etnologia da Universidade de São Paulo.

jrpellini@yahoo.com.br o poder de visualização que se tem dos dados, seja em duas ou três dimensões. Outra vantagem é a possibilidade de calcular distâncias e superfícies de fenômenos referenciados espacialmente em relação a características físicas específicas. No caso específico da arqueologia, embora o GIS ofereça um conjunto ilimitado de ferramentas de análise, cuidados devem ser tomados principalmente se considerarmos o fato de que as características arqueológicas geralmente se apresentam sobrepostas pelas características geográficas atuais. Fatores sociais, culturais, topográficos e geográficos, tinham e continuam tendo um impacto significativo sobre a maneira na qual os indivíduos se movimentavam na paisagem. Alguns destes fatores, como a localização de antigos sítios, tipos diferenciados de 
PELLINI, J.R. O uso do GIS para entender o sistema de trocas no Egito Antigo e na Núbia: mapas de circulação, uma nova abordagem para as superfícies de custo. Rev. do Museu de Arqueologia e Etnologia, São Paulo, 15-16: 209-245, 2005-2006.

cobertura vegetal, fontes de água e recursos ambientais, extensão das terras aráveis etc. podem ser reconstruídos pelos arqueólogos com o auxilio das novas tecnologias relacionadas aos sistemas de informação geográfica.

Dada a abrangência e a infinidade dos tipos de análise espacial que nos oferecem os softwares de GIS, eles se tornam especialmente indicados para o estudo dos sistemas de troca. Como salientaram Bell, Wilson e Wickhan (2002), os sistemas de informação geográfica são uma ferramenta poderosa e indispensável nos estudos dos problemas relacionados às rotas comerciais e de comunicação. Mas computar e modelar as antigas rotas requer um grande esforço na reconstrução daqueles elementos dentro da antiga paisagem que direcionavam os movimentos ao longo de uma certa região.

\section{O GIS e o estudo dos sistemas de troca}

Nos três últimos anos, análises de custo de superfície têm sido utilizadas na tentativa de modelar o movimento dos indivíduos através da paisagem. Muitos softwares de GIS oferecem a possibilidade de gerar superfícies de custo. Estas superfícies de custo podem ser consideradas como um produto baseado em proximidades contínuas que levam em conta não somente a proximidade, mas também o caráter do terreno sobre o qual as proximidades são calculadas. Superfície de custo, assim como distância, é um modelo matemático cujo significado arqueológico não é fixado, cabendo ao pesquisador definir os parâmetros de análise. Uma superfície de custo é, portanto, um modelo computadorizado da paisagem no qual para cada parte da superfície é assinalado um valor, ou custo, que representa o esforço ou energia requerida para alcançar um certo ponto a partir de um ponto pré-determinado. O custo total é determinado por um logaritmo que incorpora não só as distâncias em relação ao ponto final, quanto os custos adicionais relacionados a aspectos particulares da paisagem. Estes custos adicionais são determinados pelo pesquisador e são derivados de sistemas de classificação nos quais para cada característica da paisagem é determinado um certo valor de custo. Por exemplo, para se determinar a melhor rota de acesso a um determinado ponto, dentro de uma área caracterizada pela existência de savanas e florestas densas, valores diferenciados de custo devem ser assinalados para cada tipo específico de vegetação. Sendo assim, como é mais difícil caminhar dentro de florestas densas, poderíamos assinalar um valor de custo de 6 para as áreas de floresta e um valor de 2 para as áreas de savana. Quando se constrói um modelo de análise de superfície de custo, o valor de custo de cada classe é estabelecido em relação à classe de menor valor de custo. Se dentro desta mesma área existem locais que são culturalmente proibidos como, por exemplo, cemitérios ou zonas limites, poderíamos também assinalar um valor de custo para estas áreas socialmente definidas.

Os logaritmos utilizados para as análises de superfície de custo podem ser classificados em dois grandes grupos, logaritmos isotrópicos, que são aqueles que levam em conta o custo do movimento em uma superfície sem considerar a direção de tal movimento e logaritmos anisotrópicos, nos quais a direção do movimento que afeta o custo de deslocamento passa a ser considerada.

\section{Análises de superfície de custo isotrópicas}

Nos exemplos de análise de superfície de custo mais simples, os logaritmos requerem dois tipos de arquivos de entrada, um arquivo contendo a localização das características para as quais o custo de distância será calculado, geralmente chamado de raster de fonte, e um arquivo que contém a especificação do custo relativo de se percorrer uma dada distância dentro das unidades da paisagem, normalmente denominado superfície de fricção. Os dois tipos de arquivo necessitam a inserção de valores de custo proporcionais, relativos a uma base de custo 1 . Se, por exemplo, algum indivíduo gasta 350 calorias para percorrer uma superfície plana e 700 calorias para caminhar, na mesma velocidade ao longo de um terreno mais elevado, podemos dizer que o terreno mais acidentado tem uma superfície de fricção de valor 2. Em contrapartida, se um indivíduo gasta 175 calorias para caminhar ladeira abaixo em uma elevação, pode se dizer que a superfície de fricção é de 0.5. Em outras palavras, uma superfície com valor de fricção de 0,5 determina que será realizada metade do esforço de se cruzar uma superfície de valor 1 , assim como uma superfície de valor três requer três vezes mais esforço.

A partir dos dois arquivos de entrada o logaritmo inicia o processo de análise da superfície 
em cada raster de fonte, calculando sucessivamente o custo de se alcançar uma localidade vizinha. Sendo assim, o produto final é um modelo cumulativo do custo de se alcançar um determinando ponto na paisagem a partir de um ponto inicial. Devemos lembrar que o logaritmo de superfície de custo não modela algo real, como movimento ou dispersão, ao contrário, custo aqui é um processo abstrato sendo que a análise de custo pode representar uma grande variedade de fatores, todos dependentes do modelo inicialmente proposto. Normalmente, análises de custo têm sido utilizadas em arqueologia bem como em outras ciências para modelar o tempo ou a energia gasta no movimento entre dois pontos na paisagem.

\section{Análises de superfície de custo anisotrópicas}

Análises isotrópicas de custo são utilizadas onde o custo de retorno à base está sendo calculado ou em casos onde a direção do movimento através de uma dada superfície de fricção não afeta o custo da movimentação. Entretanto há casos nos quais a direção do movimento em uma superfície de fricção afeta diretamente o custo de distância. Este é o caso, por exemplo, das superfícies de elevação, onde um determinado custo está envolvido nos movimentos rumo às partes altas do terreno enquanto um outro custo está envolvido nos movimentos rumo às partes mais baixas.

Nestes casos uma abordagem mais sofisticada é necessária. Uma possibilidade é criar arquivos não só para a magnitude da fricção, como no caso das análises isotrópicas, mas também para a direção na qual a friç̧ão tem seu efeito amplificado. As funções matemáticas utilizadas para calcular a friç̧ão efetiva causada pelo caminhamento em relação à direção do movimento e em relação à magnitude da fricção são denominadas funções de análise anisiotrópicas. A função geral determina que:

$$
\text { Custo }=\text { Custo }{ }_{\text {base }} \mathrm{xF}_{\max }{ }^{\cos \mathrm{k}(\boldsymbol{\alpha})} \text {, }
$$

em que custo base é o custo, F max é a magnitude da fricção, a é o ângulo entre a direção do caminhamento e a direção da fricção e K é a constante utilizada para efetivar o custo entre $\mathrm{a}=0^{\circ}$ e a $=180^{\circ}$, ou seja a constante K é utilizada para calcular o rumo no qual a elevação modifica os valores de fricção.
A criação de uma superfície de fricção determina a natureza da análise. Onde o resultado esperado é um modelo do gasto de energia, então a superfície de fricção precisa representar a energia dispensada no caminhamento em relação a uma distância fixa. Se considerarmos que a energia dispensada é apenas um produto da elevação do terreno, então a relação precisa ser postulada entre a elevação e a energia.

A forma mais simples de superfície de fricção é o chamado modelo de inclinação. Neste caso, o requerimento básico é o valor da altitude. Teoricamente o custo de transposição de uma superfície aumenta conforme aumenta a inclinação do terreno. Uma abordagem mais sofisticada converte os valores da inclinação em velocidade de deslocamento através da função Hiker. A função Hiker, desenvolvida pelo geógrafo Waldo Tobler (1993: 4), tem sido utilizada com sucesso por arqueólogos e etnógrafos. A função Hiker se dá pela fórmula

$$
\mathrm{T}=\mathrm{D} /(6 \exp (-3,5 \mathrm{X} \text { abs }(\mathrm{S}+0,05))) \text {, }
$$

onde T igual a tempo necessário para cruzar cada célula do Modelo de Elevação Digital, D igual à distancia através de cada célula e $\mathrm{S}$ igual à inclinação do terreno em cada célula. A aplicação desta fórmula produz uma superfície de custo que mede a quantidade de tempo necessário para se transpor cada célula. A grande vantagem deste método é a possibilidade da criação de mapas que representem o gasto calórico envolvido em cada tipo de deslocamento. Outra vantagem é a possibilidade de discutir, com base nos mapas de gasto calórico, a existência de paragens e centros de abastecimento ao longo de uma dada rota, avaliabilidade de recursos e por fim quantidade e tipos necessários de alimento a serem levados no caminho.

Há dois pontos importantes que devem ser incluídos nos chamados modelos de inclinação. Em primeiro lugar não devemos considerar que o custo de transpor uma inclinação é diretamente proporcional ao grau de inclinação, sendo assim, caminhar em um terreno com uma inclinação de $45^{\circ}$ não é simplesmente 45 vezes mais difícil que caminhar em uma superfície plana com $0^{\circ}$ de inclinação. O custo relativo de se caminhar em superfícies inclinadas deve ser expresso como a média das tangentes dos ângulos de inclinação.

O segundo ponto a ser considerado quando utilizamos modelos de inclinação para a criação de 
PELLINI, J.R. O uso do GIS para entender o sistema de trocas no Egito Antigo e na Núbia: mapas de circulação, uma nova abordagem para as superfícies de custo. Rev. do Museu de Arqueologia e Etnologia, São Paulo, 15-16: 209-245, 2005-2006.

superfícies de custo é que a inclinação não exerce a mesma força uniformemente em todas as direções, isto porque quando o movimento é perpendicular à inclinação o esforço exercido é menor. Neste sentido o uso de modelos de custo de superfície anisotrópicos é mais eficiente, pois leva em conta tanto a magnitude quanto a direção do movimento entre o ponto A e B, o que produz uma superfície de custo direcional na qual a direção é calculada contra a suavidade e o aspecto da inclinação. Devido ao fato de que modelos de custo de superfície calculam o custo de deslocamento entre dois pontos, dentro de uma paisagem eles são estritamente pontuais, sendo assim, não é possível gerar superfícies de custo com a proposta de analisar movimentos bidirecionais entre múltiplos pontos dentro de uma determinada área.

Em arqueologia considera-se que o gasto tanto de energia quanto de tempo é uma função das diferenças na elevação do terreno. Esta é uma afirmação simplista, já que também outras características meio ambientais condicionam a energia gasta no deslocamento, como é o caso, por exemplo, das dunas e das áreas de cobertura vegetal densa. Devemos lembrar, como dissemos acima, que a movimentação dentro da paisagem é condicionada tanto por aspectos físicos quanto simbólicos. A existência de áreas sagradas, como cemitérios, áreas de tabu, ou o simples desejo de se passar por uma certa vila, podem ter mais influência sobre a estrutura do deslocamento do que simplesmente a topografia da área em questão. Nos casos onde temos uma área culturalmente proibida ou áreas afetadas positivamente por rotas de transporte, podemos assinalar valores de fricção diferenciados a fim de melhor contextualizar as superfícies de análise.

A maioria dos modelos de análise de superfície de custo obedece a uma estrutura interpretativa derivada em grande parte da moderna teoria econômica, que reduz a análise de custo a uma questão de racionalização das distâncias. O que temos, assim, de fato, é uma descrição sistêmica e funcional na qual os fatores sócio-culturais são retirados da análise. Nestas teorias há uma suposição implícita de que a ação dos indivíduos é estritamente econômica e que a minimização das distâncias poderia resultar na minimização do custo ou do esforço. Chisholm $(1962,1963)$ sugeriu que a minimização do custo de transporte e da distância percorrida resulta em uma concentração na produção e na distribuição dos produtos em poucos pontos. Aqui o indivíduo é visto, pela maneira como maximiza sua satisfação através da escolha de determinados meios para alcançar determinados fins. Isto acontece através de um grupo de motivações que são puramente econômicas, que não levam em conta outras motivações que possam interferir no processo. É o chamado postulado da escassez (Hopkins 1965: 348). Se de um lado o princípio da maximização separa as motivações econômicas das não econômicas, de outro o princípio da alocação abstrai-se do complexo institucional, sendo assim, a economia é vista como uma alocação racional de meios escassos para alcançar determinados objetivos. Como salientou Olsson (1965: 43), no entanto, uma certa flexibilidade tem de ser considerada nos estudos de interação e distância, não só pelo fato de que diferentes grupos e indivíduos concebem a distância de formas diferentes, mas também porque estas concepções variam de acordo com o tipo de interação, um aspecto que foi bem demonstrado por Clarke (1965) em sua análise do comércio préhistórico de itens de prestígio na Europa e Austrália. Quando analisamos esquemas de distribuição e distância devemos ter em mente que são vários os fatores que afetam as escolhas e a distância percorrida. A probabilidade de um indivíduo se mover de um local para o outro precisa ser computada como uma função das características do indivíduo (idade, raça, sexo, vida urbana ou rural etc.), das características da área estudada (formas de relevo, paisagens, formações urbanas, contexto sócio-econômico), das características dos possíveis destinos bem como das diferenças entre eles, e não apenas sob uma variável custo.

Embora as chamadas "análises de superfície de custo” estejam em parte relacionadas às teorias de minimização do esforço, devemos lembrar que custo é uma medida relativa e que varia de acordo com o sistema e com a sociedade a ser analisada. Por exemplo, para algumas pessoas, caminhar morro acima rumo a um pequeno jardim não representa custo algum, já para outras pessoas o mesmo trajeto incide em uma série de restrições, ou custo. Isto se torna ainda mais relevante se deixarmos de considerar apenas o meio físico e passarmos a considerar a paisagem como algo socialmente construído. Como salientou Gillings e Wheatley (2002), as análises de custo de superfície são modelos matemáticos que modificam uma certa superfície e cujo significado não é fixado, cabe aos 
PELLINI, J.R. O uso do GIS para entender o sistema de trocas no Egito Antigo e na Núbia: mapas de circulação, uma nova abordagem para as superfícies de custo. Rev. do Museu de Arqueologia e Etnologia, São Paulo, 15-16: 209-245, 2005-2006.

pesquisadores definirem os parâmetros de análise. Portanto, quando se está interessado em análises que visem apenas a determinação de rotas que incidam em menor custo dentro do ambiente físico, as implicações metodológicas são claras. Mas quando os parâmetros de análise passam a integrar fatores sócio-culturais outros que não apenas a minimização do esforço, os resultados são mais abrangentes e não tão reducionistas.

\section{O objeto de estudo}

A Núbia até o inicio do século XX era uma região relativamente inexplorada e assim pouco conhecida, pelo menos do ponto de vista arqueológico. Com os progressivos aumentos do lago da represa de Aswan e a conseqüente construção do lago Nasser que abasteceria a futura represa, a área culturalmente rica onde se localizava a antiga Núbia seria inundada. Devido a estes fatores, três campanhas de salvamento ocorreram na Núbia com o objetivo de resgatar e preservar os restos arqueológicos desta área, sendo a maior delas promovida pela UNESCO na década de 60 .

A primeira etapa de salvamento dos restos arqueológicos da Núbia ocorreu entre os anos de 1907 e 1911 em razão da necessidade de se aumentar a capacidade do lago que abastecia a represa, fato que iria resultar na inundação de grande parte do vale do Nilo no país. Entre 1929 e 1934 foi necessário realizar mais um aumento na capacidade do lago, e assim uma nova campanha de salvamento teve inicio. Entre as inúmeras equipes de pesquisadores que foram trabalhar nestas duas etapas de salvamento se destaca a equipe da Universidade da Pensilvânia chefiada por David Randall-MaIver e Leonard Wolley, que trabalharam nos sítios de Karanog, em alguns sítios meroíticos da região e em Areika, um grande cemitério do grupo C. Outra equipe que muito se destacou foi a do Fine Arts Museum de Boston em conjunto com a Universidade de Harvard sob a coordenação do Prof. George Reisner, que ao longo dos 18 anos em que trabalhou na Núbia conseguiu estudar e escavar os sítios de Kerma, Napata, Meróe e Nuri. Foi o Prof. Reisner quem primeiro identificou e estudou os grupos A e C. Em 1960, houve, pela terceira vez, a necessidade de se realizar um projeto de salvamento arqueológico na Núbia, mas, neste caso, em um grau muito maior do que nas outras etapas. A campanha foi liderada e promovida pela UNESCO que denominou o projeto de Campanha Internacional para o Salvamento dos Monumentos da Núbia. Os diversos projetos de salvamento na região núbia fizeram com que o mundo inteiro pela primeira vez desviasse seus olhares para esta área. Uma equipe internacional de arqueólogos realizou um imenso esforço a fim de investigar e resgatar os restos arqueológicos que seriam submergidos após a construção do lago Nasser. Assim, graças a estas campanhas de salvamento, a Núbia é considerada uma das regiões mais pesquisadas do mundo. Isto não significa necessariamente que todo o material escavado e que todos os sítios arqueológicos tenham sido pesquisados de maneira correta e eficiente. Como afirmou Williams (1992), muito sítios arqueológicos foram perdidos pela ineficiência de alguns pesquisadores e pela simples falta de metodologia, fruto do gigantesco afluxo de pesquisadores com as mais diferentes formações. Isto tem se tornado um sério obstáculo para o completo entendimento dos padrões de assentamento da região núbia.

Para nossa pesquisa escolhemos a região entre Qustul no Egito e Gamai no Sudão por ter sido uma das mais intensivamente trabalhadas durante os projetos de salvamento da Núbia. Embora estas regiões tenham sido pesquisadas por equipes diferentes, já que a região entre Qustul e Adindan contou com a participação do Oriental Institute de Chicago e a região entre Faras e Gamai tenha sido trabalhada pela Scandinavian Joint Expedition, são as áreas que em conjunto contam com as maiores e melhores publicações relativas aos sítios arqueológicos datados do Novo Império e aos resultados dos salvamentos.

\section{IIIa. Qustul, Adindan e Serra}

Os sítios arqueológicos de Qustul e Adindan fazem parte da área de salvamento sul, concedida ao Instituto Oriental de Chicago em 1960, pelo governo do Egito, estendendo-se, tanto do lado oeste quanto do lado leste do banco do rio Nilo, do norte do Templo de Abu Simbel até a fronteira com o Sudão. A concessão excluía Abu Oda, Gebel esh Shamis, Gebel Ada e os templos de Abu Simbel. Aárea assim incluía quase $20 \mathrm{~km}$ da extensão do rio Nilo de norte para sul (em relação à direção do rio) e dois terços da vila de Abu Simbel, com Qustul e Adindan no banco esquerdo do rio e a vila de Ballana no banco direito. Como 
PELLINI, J.R. O uso do GIS para entender o sistema de trocas no Egito Antigo e na Núbia: mapas de circulação, uma nova abordagem para as superfícies de custo. Rev. do Museu de Arqueologia e Etnologia, São Paulo, 15-16: 209-245, 2005-2006.

apontou Williams (1992) a área da concessão em geral não difere das outras áreas ao redor do Nilo na baixa Núbia. No aspecto geomorfológico, o cenário que encontramos abaixo do Wadi es Sebua apresenta pequenas planícies aluviais em forma de crescente ou terraços, cada um contendo uma vila. Em poucos casos como em Teshka, a vila ocupa mais do que uma planície. Formações montanhosas circundam grande parte do vale do Nilo ao longo da área de concessão. No leste são as encostas do platô de Abu Simbel, constituído de arenito núbio erodido e preservado sobre sólidas capas, mas cortados por wadis perto do rio. Para nordeste as encostas se aproximam do rio ao lado da vila moderna de Abu Simbel alcançando o rio em Gebel Ada. Exceto pela presença de pequenas ilhas no rio, o aspecto geral de Qustul era típico de uma vila núbia moderna. O banco do rio era ocupado por matas e palmeiras, a vertente do rio por campos seguido por uma coluna ou pares de colunas de casas núbias. A quase $2 \mathrm{~km}$ da vila de Qustul os grandes túmulos do grupo $\mathrm{X}$ foram encontrados.

Em Adindan o gebel estava mais próximo aos campos e somente umas poucas casas foram descobertas ao longo de sua base. Muitas foram construídas sob o próprio gebel freqüentemente em colunas com a orientação leste-oeste. Perto do limite sul do crescente de Adindan, o gebel era baixo e as casas tinham as mesmas características de Qustul, sendo que a vila terminava a cerca de 500 m da fronteira com o Sudão. Em Qustul, após 1930, um grande grupo de casas foi construído no limite leste da baixa planície, de costas para o gebel, deixando o espaço do terraço desértico entre os dois grupos. No limite sul da vila o espaço entre os dois grupos aumentou, o primeiro em cultivo e o segundo em um gebel mais proeminente.

Mais a sudeste temos o baixo arenito núbio em meio a um solo pedregoso, área onde se localiza o sítio de Serra. A principal diferença entre a antiga e a moderna paisagem neste ponto foi uma pequena mudança do leito do Nilo na direção oeste, o que aumentou a quantidade de terras aráveis no lado leste da margem. Assim como nos casos de Qustul e Adindan, uma série de pequenas casas se localizava nas proximidades do sítio.

\section{IIIb. Faras}

Também como parte dos projetos de salvamento dos sítios e monumentos da Núbia, uma equipe de pesquisadores escandinavos, sob a coordenação de Torngny Save Soderbergh, foi convidada pelo diretor geral da UNESCO em 1959 para dirigir o regaste dos sítios arqueológicos entre a região de Faras e Gamai no Sudão. A parte norte da concessão, autorizada pelo Departamento de Antiguidades do Egito e do Sudão, incluía os distritos modernos de Faras, Serra, Debeira, Ashkeit e Sahaba. A parte sul compreendia as áreas de Wadi Halfa, Halfa Degheim, Abka e Gamai.

Uma das principais características da região entre a fronteira do Egito com o Sudão e a segunda catarata do Nilo são as faixas estreitas de depósitos aluviais entre o rio e a formação estrutural Inselberg do gebel (também chamado de paisagem mesa). Três diferentes depósitos circundam esta área: o moderno aluvião a $120 \mathrm{~m}$ do nível do rio, o baixo depósito limoso a $130 \mathrm{~m}$ do nível do rio e silt alto a $140 \mathrm{~m}$ do nível do rio. Assim, a sucessão consiste de um terraço de $10 \mathrm{~m}$ de silt cinza resistente e outro terraço, com $20 \mathrm{~m}$, com depósitos de areia.

Seguindo o Nilo para o sul, o Wadi Serra delimita os distritos de Serra e Debeira. Aqui a área de aluvião começa ao longo do Nilo na direção sul da costa arenosa. Esta área, que é rica para o cultivo, se estende ao sul ao longo do Nilo na direção do distrito de Askheit. Em sua porção norte a área é coberta por uma areia de formação eólica, sendo muito utilizada para o plantio de tâmaras. Ao norte da área de cultivo há imensas capas de areia, muitas das quais eram habitadas antes da inundação de 1946, sendo que o mesmo tipo de formação ocorre ao norte do Wadi Halfa. Este tipo de formação constitui uma espécie de "ilha” de areia no meio das áreas de cultivo entre Debeira e Askheit. Ao sul destas ilhas estava localizada a vila de Fadrus. A parte norte da ilha, chamada de Komangana, é coberta por uma areia profunda, levemente misturada com silt. Mais ao sul o cascalho predomina formando também um estrato profundo. Em um topo de cascalho mais duro está localizado um grande cemitério do Novo Império, o sítio 185 foco de nossas análises.

A fim de possibilitar uma análise mais detalhada tanto dos sítios, mas principalmente entre os sítios estudados, foram estabelecidas fases de ocupação para os cemitérios de Qustul, Adindan, Serra e Faras. O principal problema em se tentar definir uma cronologia para as tumbas com as quais 
PELLINI, J.R. O uso do GIS para entender o sistema de trocas no Egito Antigo e na Núbia: mapas de circulação, uma nova abordagem para as superfícies de custo. Rev. do Museu de Arqueologia e Etnologia, São Paulo, 15-16: 209-245, 2005-2006.

estamos trabalhando diz respeito principalmente à reutilização das covas de enterramento em diferentes períodos de tempo. Como apontou Williams (1975), embora a prática de enterramentos individuais não fosse desconhecida, este tipo de enterramento não era usual entre egípcios e núbios durante o Novo Império. Em geral as covas escavadas inicialmente eram aprofundadas a fim de receberem novas câmaras, que eram posicionadas seja nas extremidades da câmara principal seja em suas laterais, o que possibilitava que novos enterramentos fossem realizados. A fim de solucionar este problema dois fatores foram considerados. Em primeiro lugar foi analisada a evolução estratigráfica de cada uma das tumbas a partir dos aspectos deposicionais e pós deposicionais. Tais aspectos se relacionam principalmente com as modificações e distúrbios ocorridos nos cemitérios e nas tumbas a partir do momento de sua construção. Em segundo lugar foram consideradas as diferenças e similaridades estilísticas relativas ao equipamento funerário proveniente de cada um dos enterramentos. Com isso pudemos definir cinco diferentes fases de ocupação para as tumbas estudadas. As fases aqui estipuladas se baseiam não só na cronologia aplicada por Williams (1992) aos cemitérios escavados pelo Instituto Oriental, mas também à cronologia aplicada por Säve-Söderbergh (1990) aos sítios da SJE e às diferenças estratigráficas e pós deposicionais. A chamada Fase I cobre o período entre o início da $18^{\text {a }}$ dinastia até o início do reinado de Hatshepesut (1550-1479 a.C.). Este período é chamado por Nordstrom (1972) de período Pré Hatshepesut. Já a segunda fase de ocupação, Fase II, abrange os reinados de Hatshepesut e Tutmósis III (1479-1427 a.C.). A fase seguinte, Fase III, abriga os reinados de Amenófis II e Tutmósis IV (1427-1391 a.C.). Na Fase IV estão incluídos o reinado de Amenófis III e o período amarniano (1391-1323 a.C.). Por fim temos a Fase $V$ que vai do final do período amarniano até o final da $18^{\mathrm{a}}$ dinastia e início da $19^{\mathrm{a}}$ dinastia (1323-1300 a.C.).

Além da definição das fases de ocupação para os cemitérios núbios aqui analisados, foi necessário padronizar a nomenclatura utilizada por ambas as equipes de escavação para a descrição e catalogação dos objetos, principalmente no que se refere aos objetos cerâmicos. Os objetos descobertos nas tumbas foram assim reduzidos a onze categorias; ânforas, garrafas alongadas, jarros, jarros de estocagem, jarros carenados, jarros de vinho, suporte, tigela, objetos importados, objetos de metal e, por fim, objetos de pedra. Para cada fase de ocupação foi confeccionada uma matriz de correlação (Pellini 2005). Os resultados da correlação entre estas categorias nos mostram, por exemplo, que as ânforas estão intimamente relacionadas aos jarros de vinho e aos objetos importados independentemente da fase a ser analisada. Durante a Fase IV surge também uma associação entre as ânforas e os jarros carenados, que perdura até a fase V. O índice de associações das ânforas na Fase I e na Fase II é idêntico, sendo que aumenta progressivamente nas Fases III, IV e V, o que significa dizer que as ânforas passam a ter um maior número de objetos correlacionados a ela. No caso dos jarros de vinho o que vemos é que o índice de correlação se mantém quase inalterado em todas as fases de ocupação, estando sempre associados às ânforas, objetos importados e, nas Fases III, IV e V, também aos jarros de estocagem. Já em relação aos jarros de estocagem, não se observa nenhuma associação destes objetos com quaisquer outros nas Fases I e II, sendo que nas fases seguintes passam a estar associados aos objetos importados e aos jarros de vinho. No que se refere aos objetos de metal, eles aparecem associados aos objetos de pedra na Fase I e aos objetos importados e novamente os objetos de pedra na Fase V.

Se passarmos a analisar a questão quantitativa e sua relação com as fases de ocupação, perceberemos que há um padrão de deposição dos objetos nas tumbas. Como pudemos observar em nossa tese de doutoramento, temos um pico na quantidade de objetos na Fase II e outro na Fase IV, sendo que tanto as tigelas quanto os jarros comuns apresentam o mesmo tipo de curva de regressão. Jarros de vinho, ânforas e suportes, apresentam não somente o mesmo tipo de curva de regressão, mas também uma magnitude muito semelhante, o que ressalta mais uma vez a grande correlação entre estes itens. No caso dos demais objetos, percebe-se uma pequena tendência de aumento na Fase IV, mas não tão evidente como no caso das ânforas.

Quando passamos a analisar a questão relativa à matéria prima utilizada para a confecção dos objetos cerâmicos pudemos observar o absoluto predomínio, cerca de $85 \%$ de todo o 
PELLINI, J.R. O uso do GIS para entender o sistema de trocas no Egito Antigo e na Núbia: mapas de circulação, uma nova abordagem para as superfícies de custo. Rev. do Museu de Arqueologia e Etnologia, São Paulo, 15-16: 209-245, 2005-2006.

material, das argilas aluviais, representadas pela fábrica $^{1}$ Nilo B/C. Apenas $15 \%$ dos objetos identificados foram confeccionados com argila calcária.

Como ressaltou Bourriau (1998: 5), já existe um certo consenso, pelo menos para o período compreendido entre o Antigo Império e Segundo Período Intermediário (2920-1550 a.C.), que Alto e Baixo Egito seguiam diferentes tradições ceramistas, principalmente no que se refere à utilização das argilas calcárias. Vasilhames confeccionados com a fábrica MC eram feitos no Baixo Egito, enquanto os objetos confeccionados com as fábricas MA2, MA3 e MB eram preferencialmente produzidos no Alto Egito, na região de Tebas. Todas estas fábricas eram utilizadas, de maneira geral, para vasos de estocagem. Ainda segundo a autora, se pudermos identificar os tipos de fábricas presentes no material cerâmico, poderemos, por inferência, postular o local de origem dos vasilhames. Estas informações podem ser utilizadas não só para refinar as datações da cerâmica egípcia, particularmente do Novo Império, como também para melhorar nosso conhecimento sobre os contatos regionais praticados naquela época (Nicholson e Bourriau 1992).

É nossa opinião que, pelo menos aparentemente e no caso específico dos sítios da Núbia com os quais estamos trabalhando, a presença de objetos confeccionados com argila calcária pode representar um certo índice de status, ou pelo menos, algum tipo de conexão do sepultado com a região do Delta, tenha sido ela feita na forma de trocas comerciais ou não. Como salientaram Bourriau (1997) e Williams (1992), as argilas calcárias eram encontradas geralmente na forma de rochas, o que significa que a extração e manuseio deste tipo de argila requeriam um certo grau de especialização. Sendo assim, como apontaram recentemente Greenough, Mallory-Greenough e Owen (1998), as argilas calcárias podem ter sido consideradas mais valiosas do que a argila aluvial comum, não só pela dificuldade de obtenção, mas por algumas de suas características como alta resistência a choque térmico e baixa permeabilidade à água.

(1) O termo fábrica, como definido por Nordström (1972), se refere ao conjunto de características tecnológicas (tipo de argila, tempero e queima) de um determinado objeto cerâmico.

\section{Um novo modelo de superfície de custo}

Com este quadro inicial em mãos foi possível delinear as bases das análises de custo de superfície a fim de modelar a circulação de produtos na área estudada.

Como afirmou Castro (1993), os atuais modelos de análise de custo de superfície tentam impor uma geometria cartesiana, abstrata e atemporal sobre uma realidade que é fundamentalmente reflexiva, subjetiva e contingente. O espaço nestes casos é visto como uma entidade puramente física, separada do tempo e expressa como um valor absoluto. Sabemos que o espaço não é na realidade um conceito cartesiano neutro, mas é socialmente construído. Sendo assim se faz necessário mapear, nas análises de superfície de custo, o meio ambiente sócio-natural, a fim de representá-lo em uma perspectiva da ecologia do espaço social, que foi definida por McGlade (1993) como ecodinâmica humana. Dentro desta perspectiva, as análises de superfície de custo incorporam não somente fatores físicos como declividade, elevação, tipos de solo, vegetação, mas também fatores sócio-culturais. Partindo deste pressuposto, em nossas análises de custo de superfície, custo foi baseado em dois grupos diferenciados de parâmetros: fatores físicos e fatores sócio-culturais, que preferimos denominar de fatores contextuais.

No primeiro grupo, o dos fatores físicos, estão colocadas características como topografia, relevo, formação geológica e paleo-geológica, localização de fontes de matéria prima e quantidade de terras aráveis disponíveis. Em sua maioria estes dados foram carregados no ArcGis 9.0 através do módulo ArcGisServer. Ao todo foram utilizados sete diferentes mapas de dados para a confecção do raster de custo físico: foto do satélite MODIS de agosto de 2003, fornecida pela NASA; mapas topográficos nas escalas 1:250.000 e 1:500.000 da Egypt Survey; mapa da cobertura vegetal; mapa geológico; mapa com a localização das principais fontes de matéria prima; um mapa da rede hidrográfica. Em seguida reclassificamos cada um dos mapas de dados sob uma mesma escala para que fosse possível criar um raster de custo físico. Todos os mapas foram por fim reunidos em um único raster com o auxílio do módulo Spatial Analyst.

Para o segundo grupo foi considerada uma série de dados históricos. Fatores gerais de 
planificação como, por exemplo, a existência de pequenos agrupamentos de casas ao redor de oficinas e locais de trabalho (Kemp 1972), o posicionamento de palácios e templos em relação à arquitetura urbana (O'Connor 1989), dados como a quantidade média de vilas existentes em torno de cada cidade, a quantidade de consumo de grão e a densidade demográfica aproximada (Hassan 1990), bem como o padrão de assentamento egípcio e núbio (O’Connor 1990), também foram considerados. Tais dados foram tabulados e reunidos em um banco de dados que foi utilizado para a criação de quatro diferentes mapas de dados: um mapa com a localização dos templos, centros administrativos e vilas da Núbia; um mapa com a planificação urbana de alguns destes templos e vilas; mapas de densidade demográfica estimada e consumo de calorias. Estes quatro mapas de dados foram somados dando origem ao raster de custo contextual.

O passo seguinte foi reunir o raster de custo físico e o raster de custo contextual em um raster final que representasse o custo geral de superfície dentro da área estudada. Para tanto, mais uma vez recorremos ao módulo Spatial Analyst a fim de somar os dois rasters. O resultado final foi um raster de custo contextual que reunia informações físicas e sócio-culturais da área de estudo.

\section{IVa. Mapas de circulação}

Com a criação do raster de custo contextual, passamos à confecção dos mapas de distribuição dos objetos arqueológicos escavados nas tumbas. Para cada objeto em cada fase de ocupação foi confeccionado um mapa de distribuição a partir do módulo Geostatistical Analyst do ArcGis 9.0. Para tanto, cada objeto arqueológico dentro da área de estudo foi plotado a partir de sua coordenada real e mapas de tendência foram gerados. Para a base de interpolação, foi utilizado o método de Inverse Distance Weighted ou IDW. Em seguida os mapas de distribuição foram reclassificados tendo em mente a idéia de que os pontos de concentração de material arqueológico representam áreas onde há um custo de superfície menor. Por fim cada mapa de distribuição foi recalculado em função do raster de custo contextual. O resultado final é uma série de mapas, que denominamos mapas de circulação, que nos mostra como cada um dos objetos analisados circula dentro da área estudada. O esquema abaixo resume os processos de confecção dos mapas de circulação.

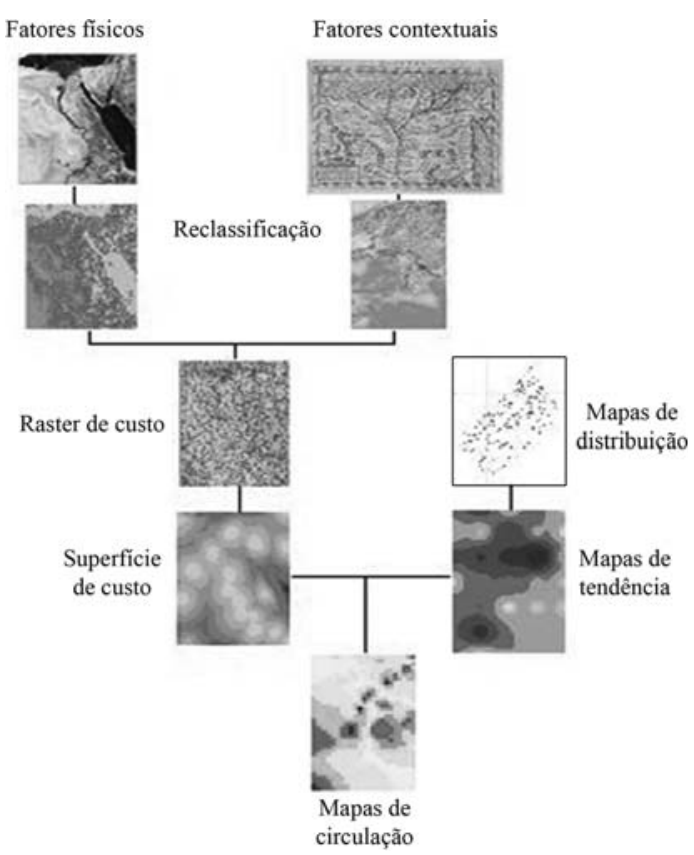

Em primeiro lugar foi confeccionado um mapa de custo de superfície baseado em fatores físicos e sócio-cultuais que denominamos mapa de custo contextual. Em seguida mapas de distribuição foram produzidos a partir da plotagem de cada um dos objetos identificados nas escavações. Tais mapas de distribuição foram reclassificados tendo em mente que áreas de adensamento de material representam áreas onde há uma maior circulação de objetos. Por fim os mapas de distribuição foram recalculados em função do mapa de custo de superfície contextual.

Nos mapas de circulação, as áreas em branco representam áreas onde há pouca ou nenhuma circulação de produtos, ou seja não há muitas interações presentes. ${ }^{2}$ Já as áreas que apresentam uma gradação entre tons de preto, representam áreas onde a circulação dos objetos é intensa, sendo que quanto maior a quantidade de tons presentes maior é a intensidade de circulação, ou seja maior o número de interações. Quanto maior a área coberta por tons de preto maior será a freqüência de interação e maior será a intensidade

(2) Por motivos relacionados à publicação, os mapas de circulação foram convertidos para tons monocromáticos. Uma versão colorida dos mapas de circulação pode ser encontrada em minha Tese de Doutorado (Pellini 2005). 
PELLINI, J.R. O uso do GIS para entender o sistema de trocas no Egito Antigo e na Núbia: mapas de circulação, uma nova abordagem para as superfícies de custo. Rev. do Museu de Arqueologia e Etnologia, São Paulo, 15-16: 209-245, 2005-2006.

de circulação dos produtos, resultado de uma série de trocas sucessivas entre um ponto e outro. Os pontos pretos isolados representam áreas onde a circulação é mais pontual. Nestes casos a circulação é focada e direcionada a um ponto especifico.

Limitaremos nossa análise às Fases I, II e V, pois é nossa opinião que estas são as mais representativas do ponto de vista da análise. Acreditamos que seria redundante trabalhar também com as Fases III e IV, pois, como vimos em nossa tese de doutoramento (Pellini 2005), os índices de correlação entre os objetos nestas fases são semelhantes e o contexto é o mesmo, ou seja, estas fases representam momentos de queda na quantidade geral e relativa de bens imobilizados nas tumbas, sendo assim é preferível trabalhar com a Fase V, pois acreditamos que esta melhor representa este momento de diminuição de bens nos cemitérios. Temos, desta maneira, a Fase I representando um momento de ascendência na quantidade de bens nas tumbas, a Fase II como o pico quantitativo e a Fase $\mathrm{V}$ como o momento em que os bens não estão mais presentes em grande quantidade.

Começando pela análise dos mapas de circulação dos jarros e tigelas, itens considerados de uso doméstico, veremos que na Fase I, início da ocupação dos cemitérios por egípcios e núbios "egcipcianizados", os vasilhames circulam dentro de uma área ainda pequena. A diferença entre as áreas em branco (áreas com ausência de circulação) e áreas com gradações de tons de preto (áreas com circulação) é quase equivalente. No caso da Fase I, embora exista circulação destes objetos, ela não é intensa e abrangente, estando confinada a poucos laços de interação. Já na Fase II, o que podemos perceber é a grande difusão da área de circulação. Neste período temos não só a cristalização da política egípcia para a Núbia como também uma maior quantidade de assentamentos na área. De acordo com as análises de rede que realizamos, é neste período que a rede de fluxo de produtos atinge sua forma mais complexa. Neste momento, tanto os jarros quanto as tigelas estão circulando intensamente por toda a área, o que significa dizer que possuem um maior número de laços de interação. A ausência de tons de banco é um dos indicativos de que estes objetos estão circulando por toda parte. Já na Fase V, período que coincide com o momento em que estes cemitérios já não estão sendo mais utilizados, jarros e tigelas passam a apresentar uma circulação diferenciada. Os jarros perdem popularidade e, embora ainda circulem, estão restritos a uma área menor. Enquanto isso as tigelas continuam, mesmo que de maneira mais reduzida, a circular com certa intensidade.

No caso dos objetos intimamente relacionados à importação, como é o caso dos jarros de vinho e das ânforas, veremos em primeiro lugar que, assim como acontece para jarros e tigelas, há uma maior circulação dos objetos importados durante a Fase II. A diferença está na intensidade da circulação. Enquanto jarros e tigelas aparecem circulando por toda a área, os objetos importados, jarros de vinho e ânforas, aparecem com uma distribuição bem mais pontual. Os jarros de vinho, diferente do que acontece com as ânforas, mantêm uma certa área de circulação ao redor de um ponto de grande intensidade. No caso de outros objetos importados, objetos cerâmicos em geral, estes deixam de circular no final da Fase II, após apresentarem uma estrutura de circulação quase idêntica à das ânforas. É de se imaginar que a importação de ânforas viesse acompanhada de outros itens produzidos fora da Núbia e que o decréscimo das importações afetasse todos os produtos que eram fruto deste tipo de comércio.

Uma circulação bem pontual ocorre também no caso dos objetos de metal e de pedra. No caso dos metais, que sempre foram monopólio de estado durante a história egípcia e que funcionavam como unidade de valor, não há uma variação muito grande entre as fases estudadas, apenas a freqüência e a intensidade da circulação é que variam um pouco entre a Fase II e V, mas a estrutura geral permanece. No que se refere aos objetos de pedra, é interessante notar que sua circulação na Fase I se apresenta bem pontual, na Fase II difusa mas sem intensidade e na Fase $V$ estrita mas com muita intensidade. Esta pequena modificação, não na estrutura de circulação, mas no sistema de acúmulo, pode ser resultado de uma maior atividade das minas de arenito e alabastro que se localizam perto dos sítios, na segunda metade da $18^{\text {a }}$ dinastia (Nicholson 2000).

Tanto os jarros carenados quanto as garrafas possuem uma estrutura de circulação similar. Ambos os itens apresentam uma circulação relativamente abrangente na Fase I, sendo que os jarros carenados mostram uma maior intensidade. Já na Fase II, os dois produtos passam a circular em uma área maior, com mais 
PELLINI, J.R. O uso do GIS para entender o sistema de trocas no Egito Antigo e na Núbia: mapas de circulação, uma nova abordagem para as superfícies de custo. Rev. do Museu de Arqueologia e Etnologia, São Paulo, 15-16: 209-245, 2005-2006.

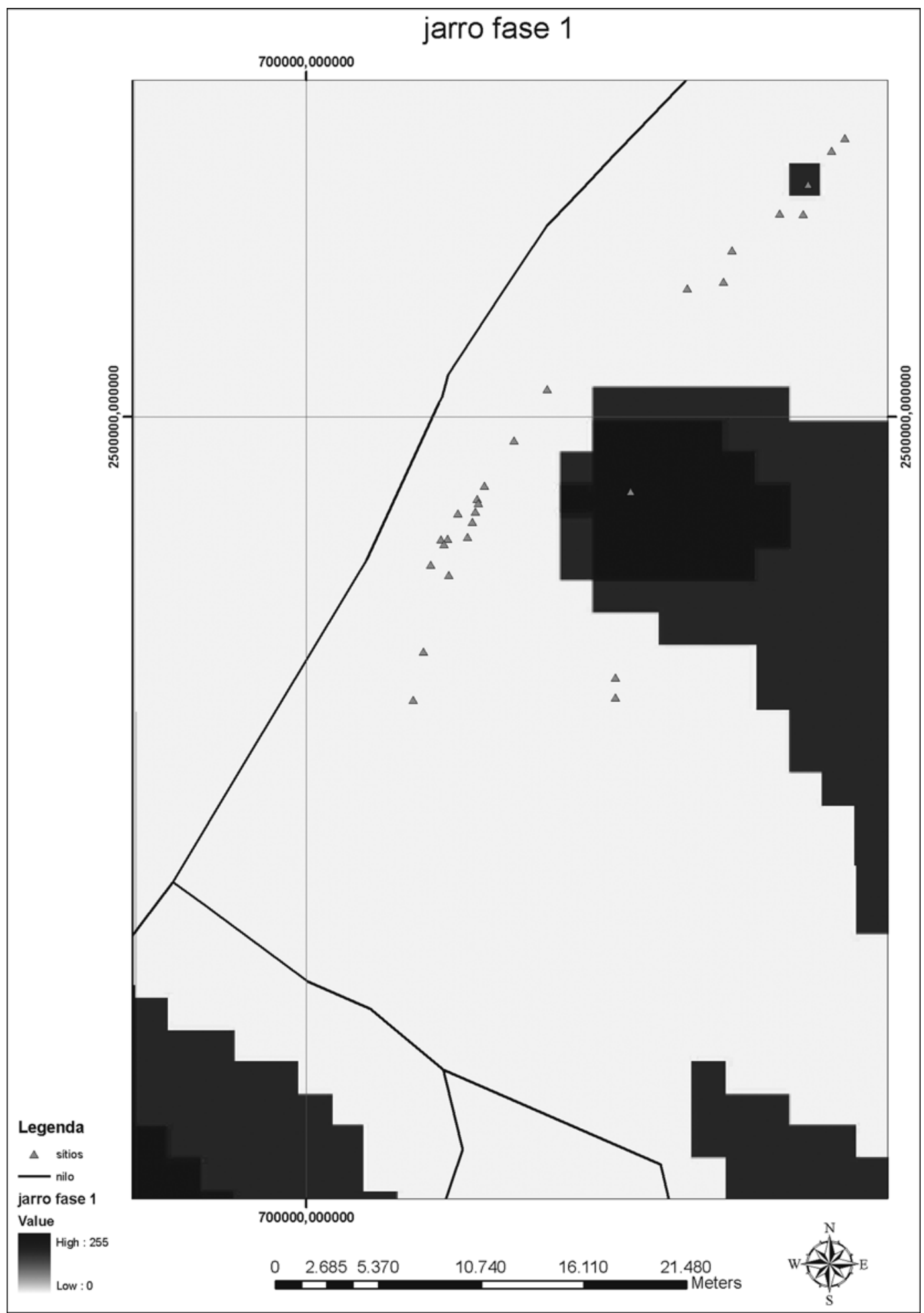


PELLINI, J.R. O uso do GIS para entender o sistema de trocas no Egito Antigo e na Núbia: mapas de circulação, uma nova abordagem para as superfícies de custo. Rev. do Museu de Arqueologia e Etnologia, São Paulo, 15-16: 209-245, 2005-2006.

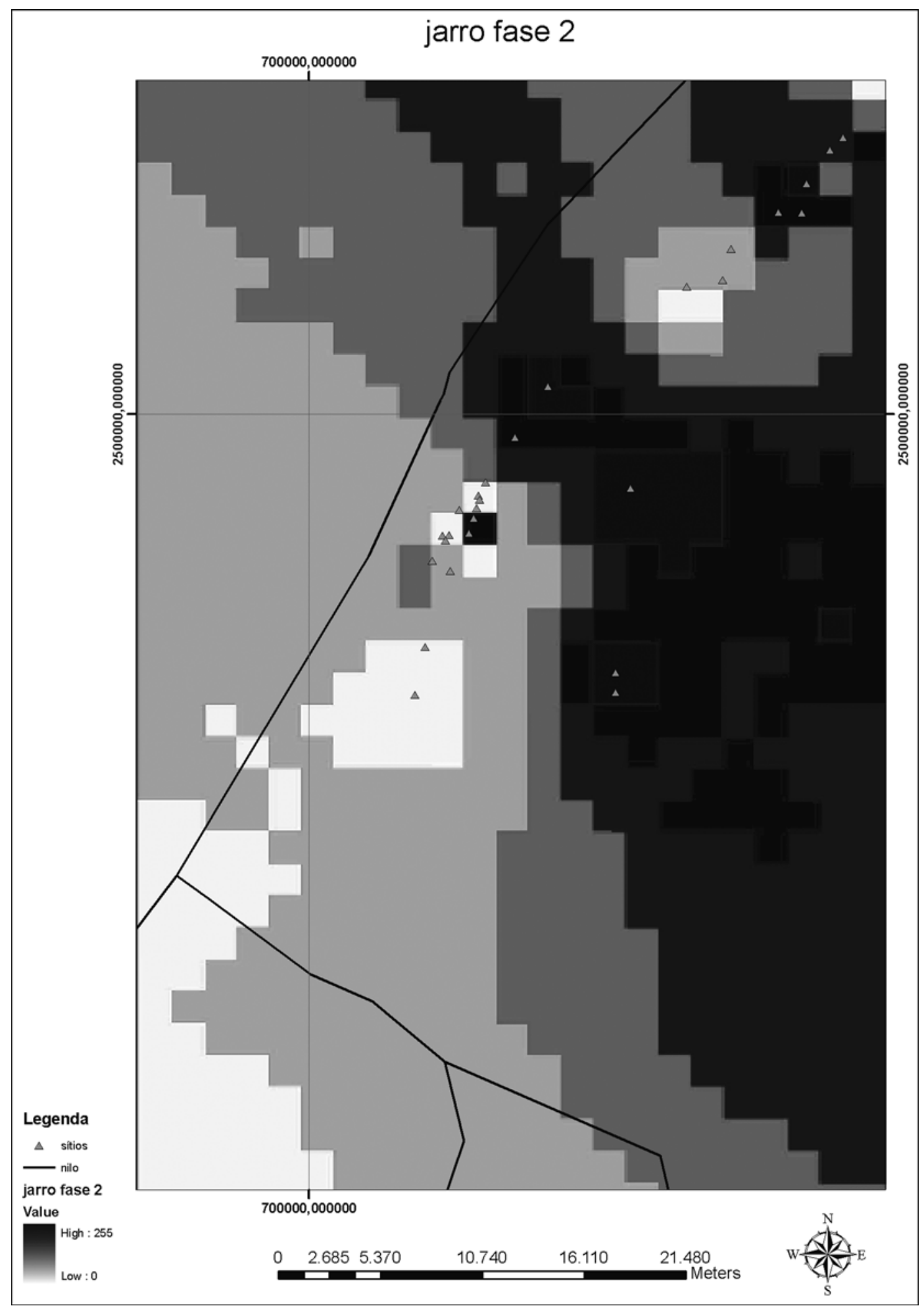


PELLINI, J.R. O uso do GIS para entender o sistema de trocas no Egito Antigo e na Núbia: mapas de circulação, uma nova abordagem para as superfícies de custo. Rev. do Museu de Arqueologia e Etnologia, São Paulo, 15-16: 209-245, 2005-2006.

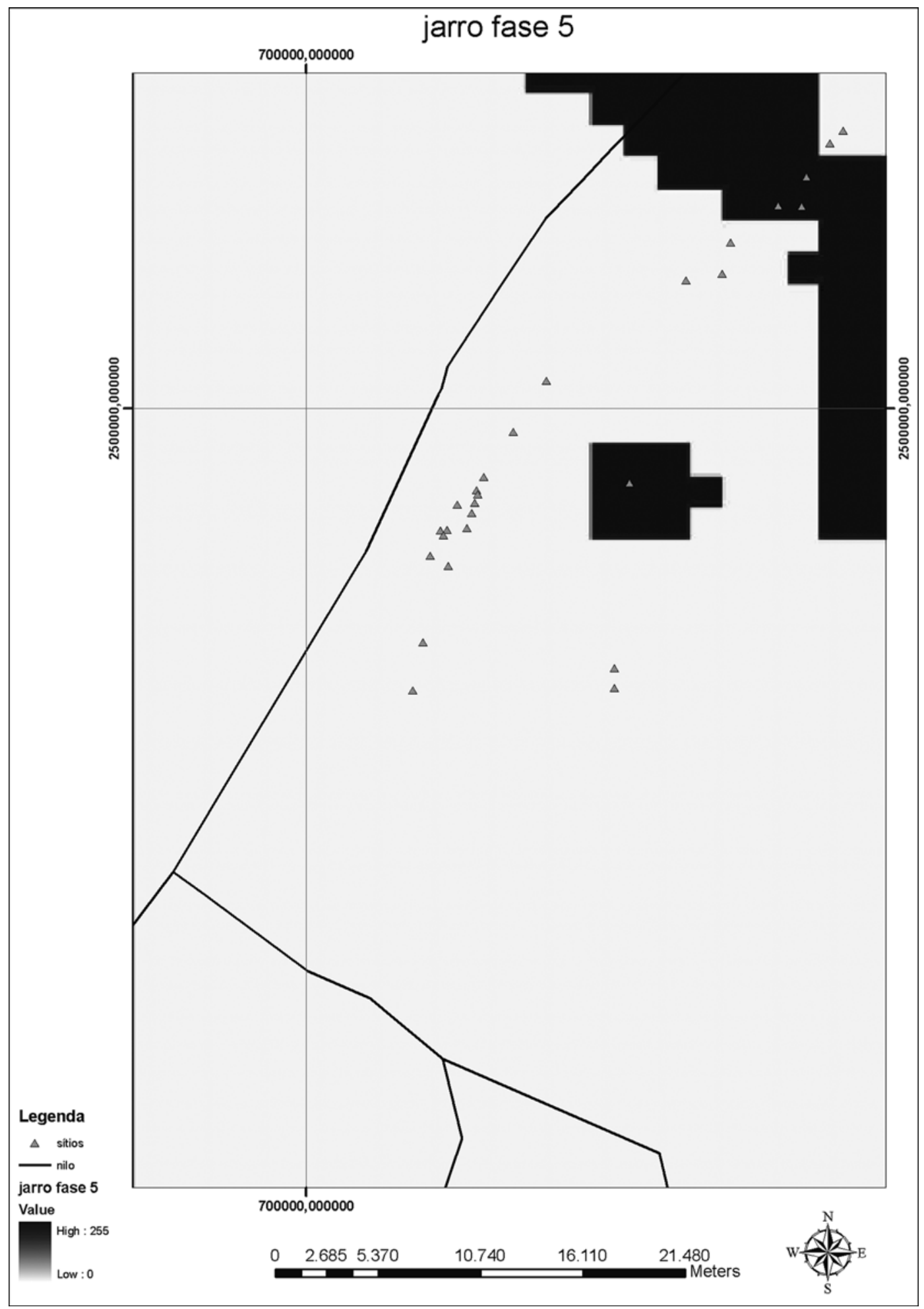


PELLINI, J.R. O uso do GIS para entender o sistema de trocas no Egito Antigo e na Núbia: mapas de circulação, uma nova abordagem para as superfícies de custo. Rev. do Museu de Arqueologia e Etnologia, São Paulo, 15-16: 209-245, 2005-2006.

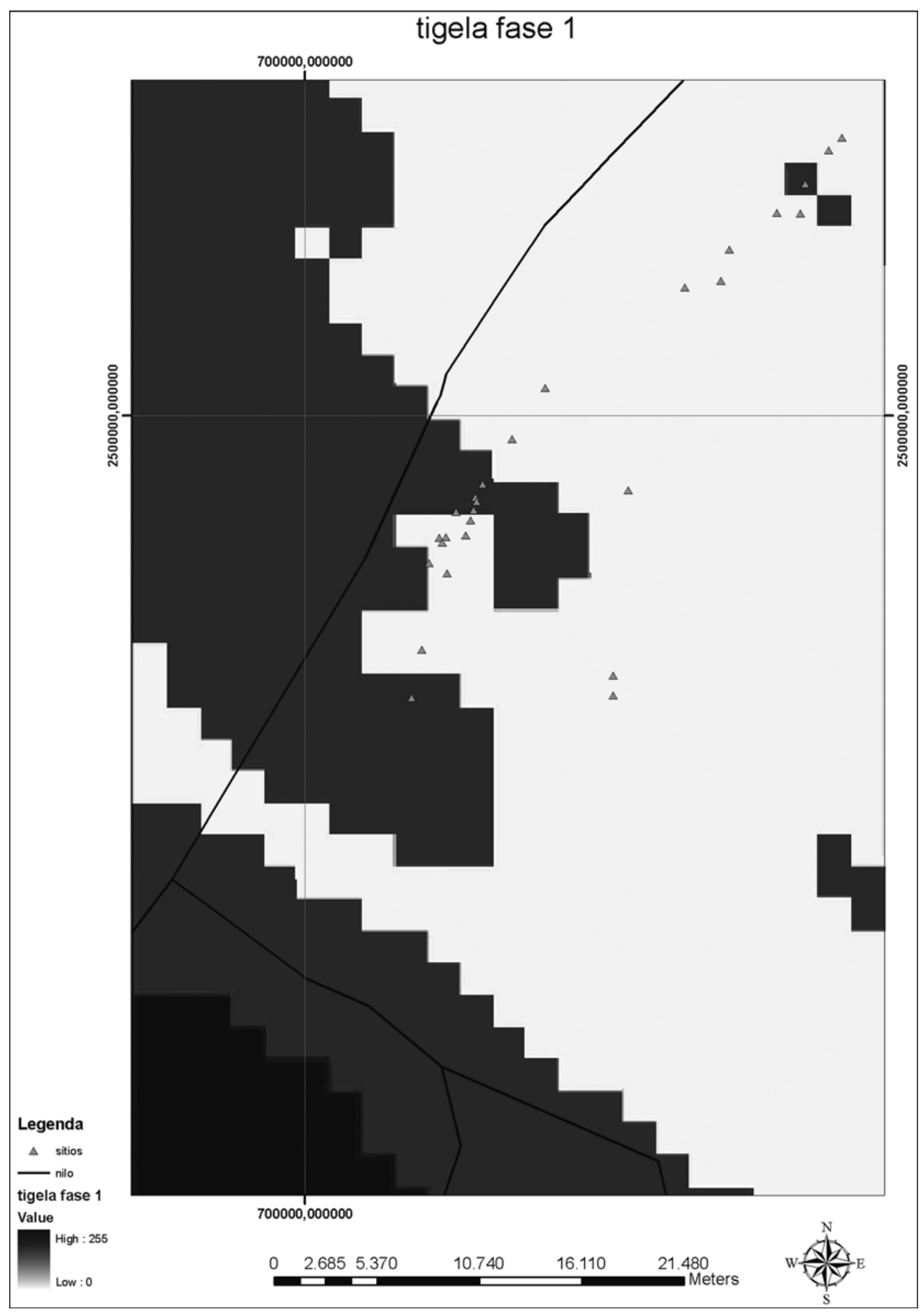


PELLINI, J.R. O uso do GIS para entender o sistema de trocas no Egito Antigo e na Núbia: mapas de circulação, uma nova abordagem para as superfícies de custo. Rev. do Museu de Arqueologia e Etnologia, São Paulo, 15-16: 209-245, 2005-2006.

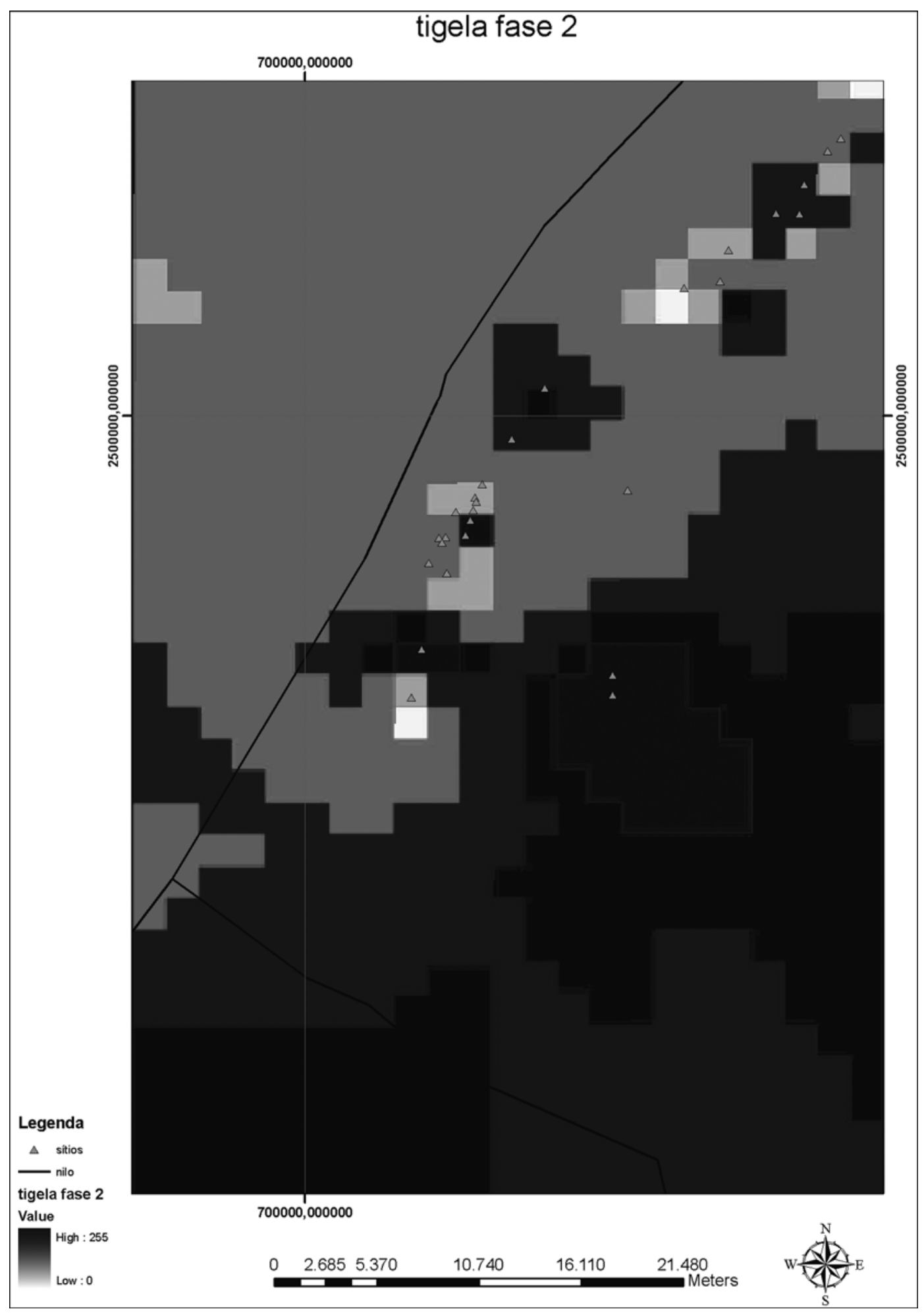


PELLINI, J.R. O uso do GIS para entender o sistema de trocas no Egito Antigo e na Núbia: mapas de circulação, uma nova abordagem para as superfícies de custo. Rev. do Museu de Arqueologia e Etnologia, São Paulo, 15-16: 209-245, 2005-2006.

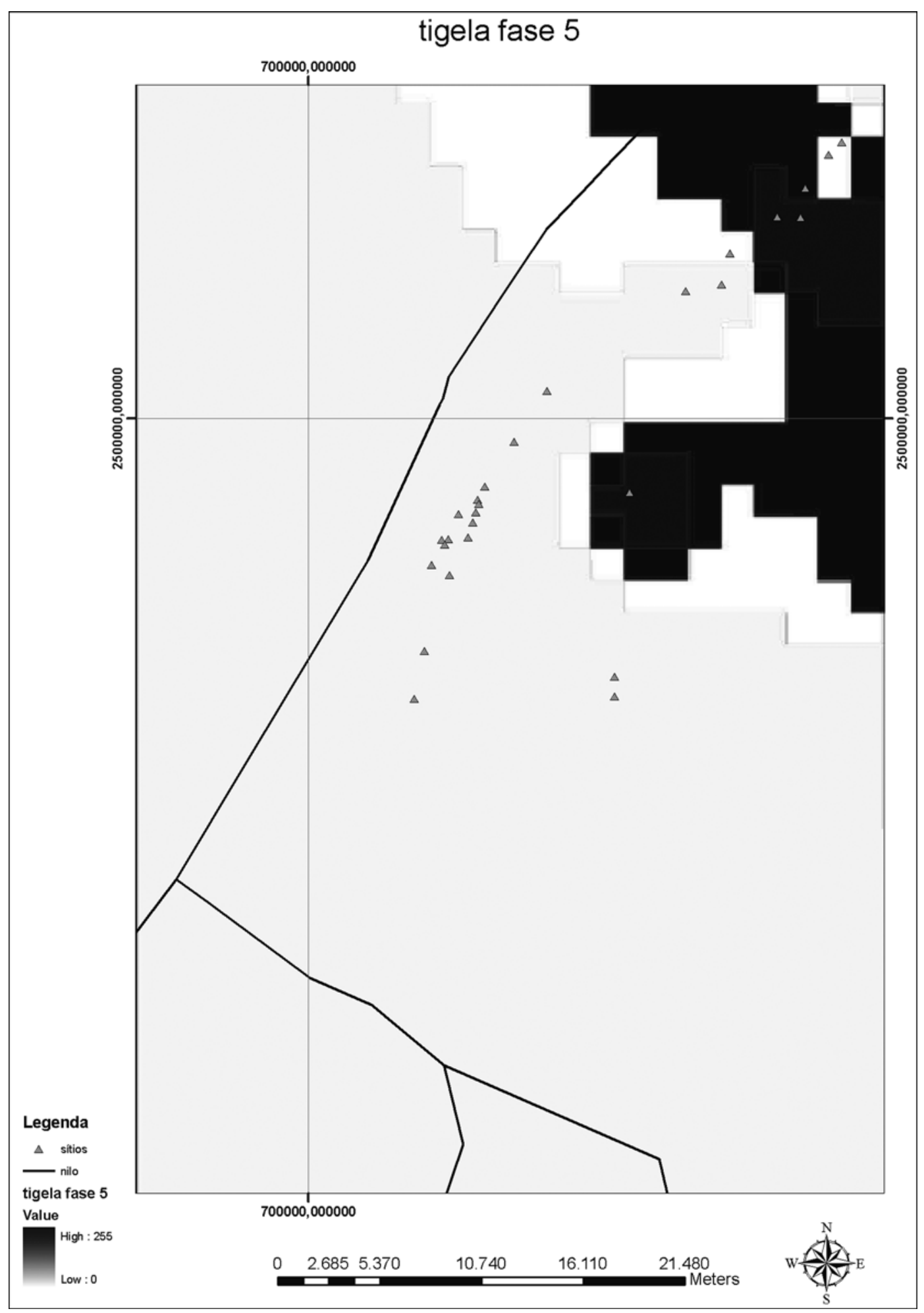


PELLINI, J.R. O uso do GIS para entender o sistema de trocas no Egito Antigo e na Núbia: mapas de circulação, uma nova abordagem para as superfícies de custo. Rev. do Museu de Arqueologia e Etnologia, São Paulo, 15-16: 209-245, 2005-2006.

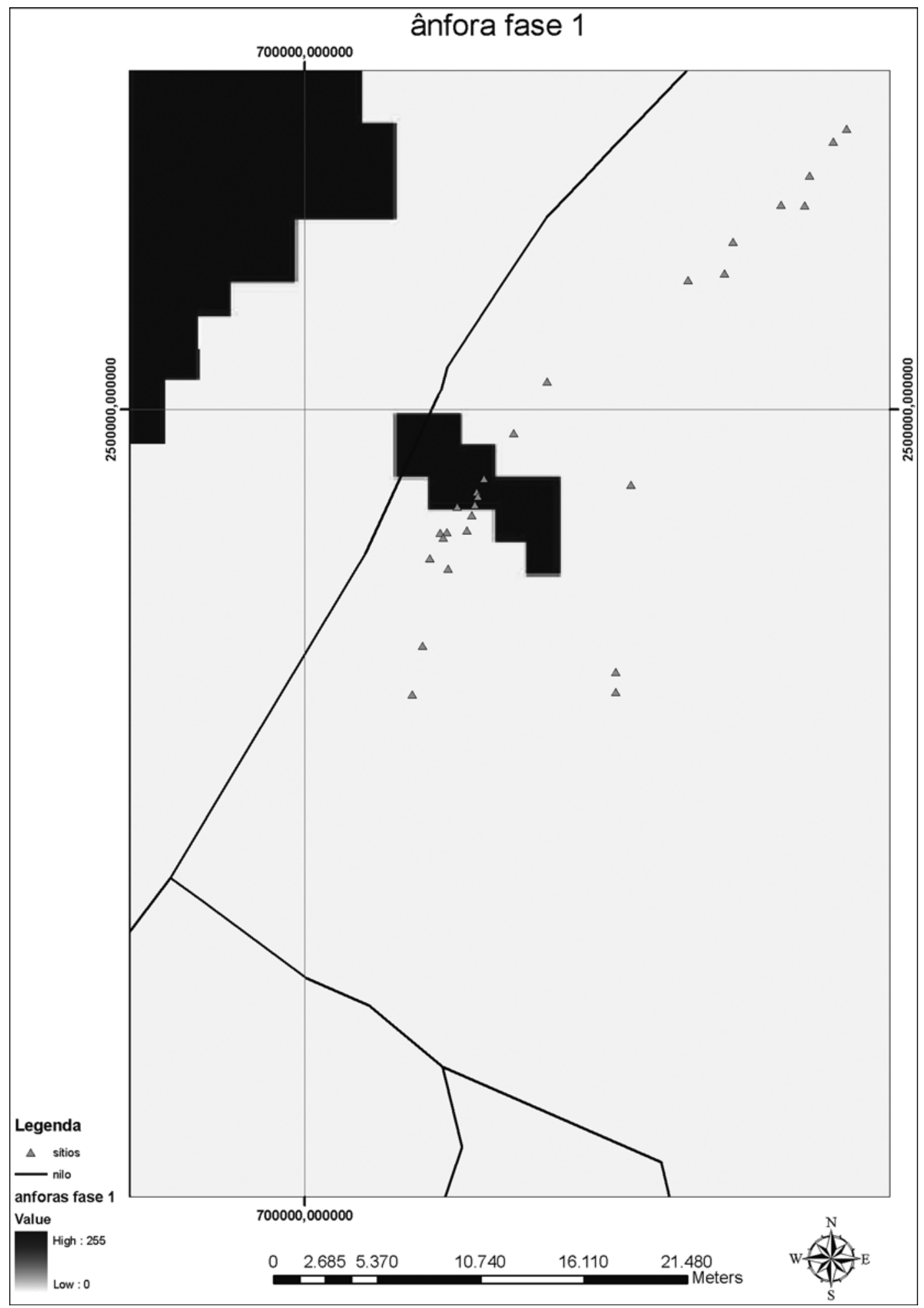


PELLINI, J.R. O uso do GIS para entender o sistema de trocas no Egito Antigo e na Núbia: mapas de circulação, uma nova abordagem para as superfícies de custo. Rev. do Museu de Arqueologia e Etnologia, São Paulo, 15-16: 209-245, 2005-2006.

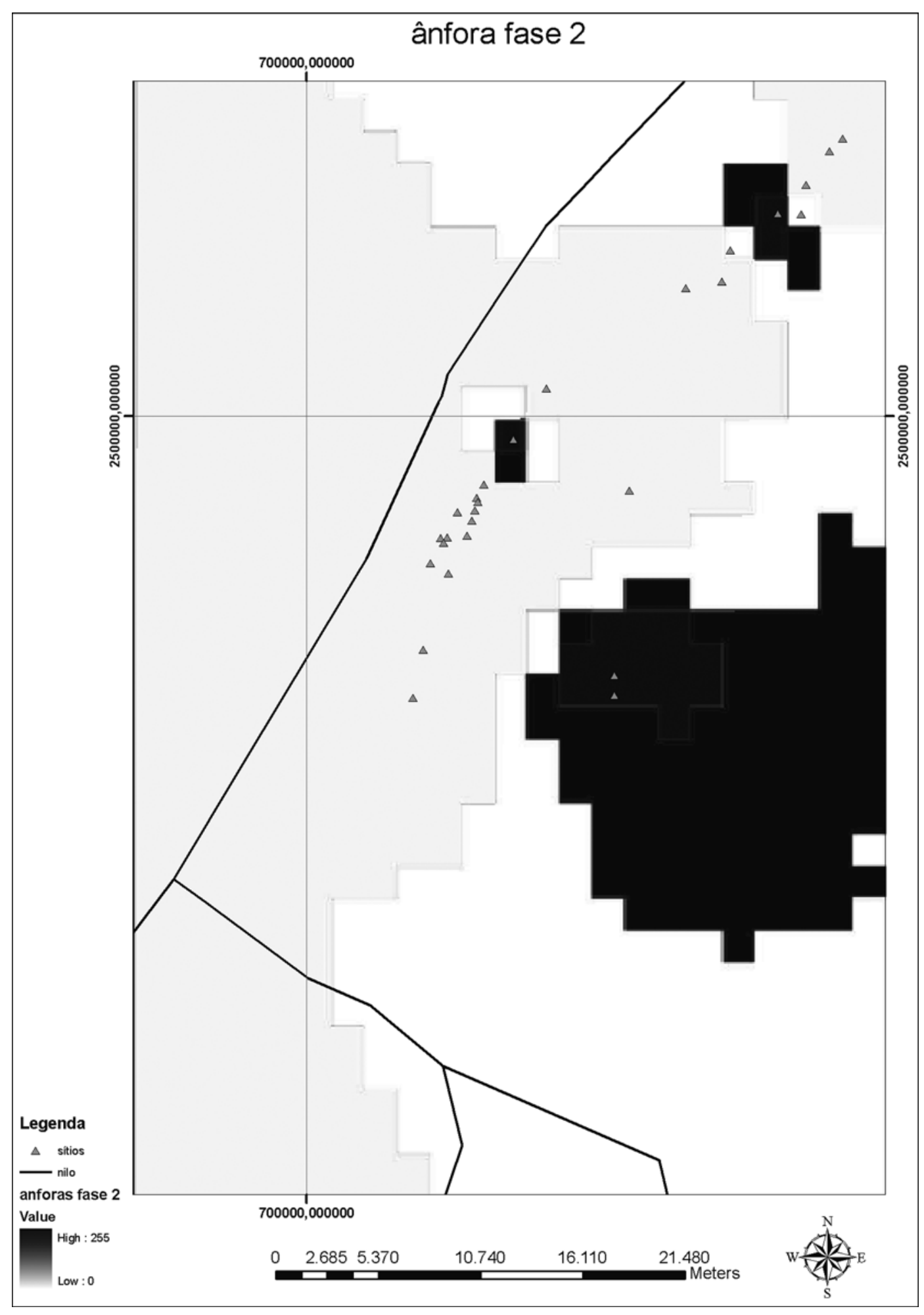


PELLINI, J.R. O uso do GIS para entender o sistema de trocas no Egito Antigo e na Núbia: mapas de circulação, uma nova abordagem para as superfícies de custo. Rev. do Museu de Arqueologia e Etnologia, São Paulo, 15-16: 209-245, 2005-2006.

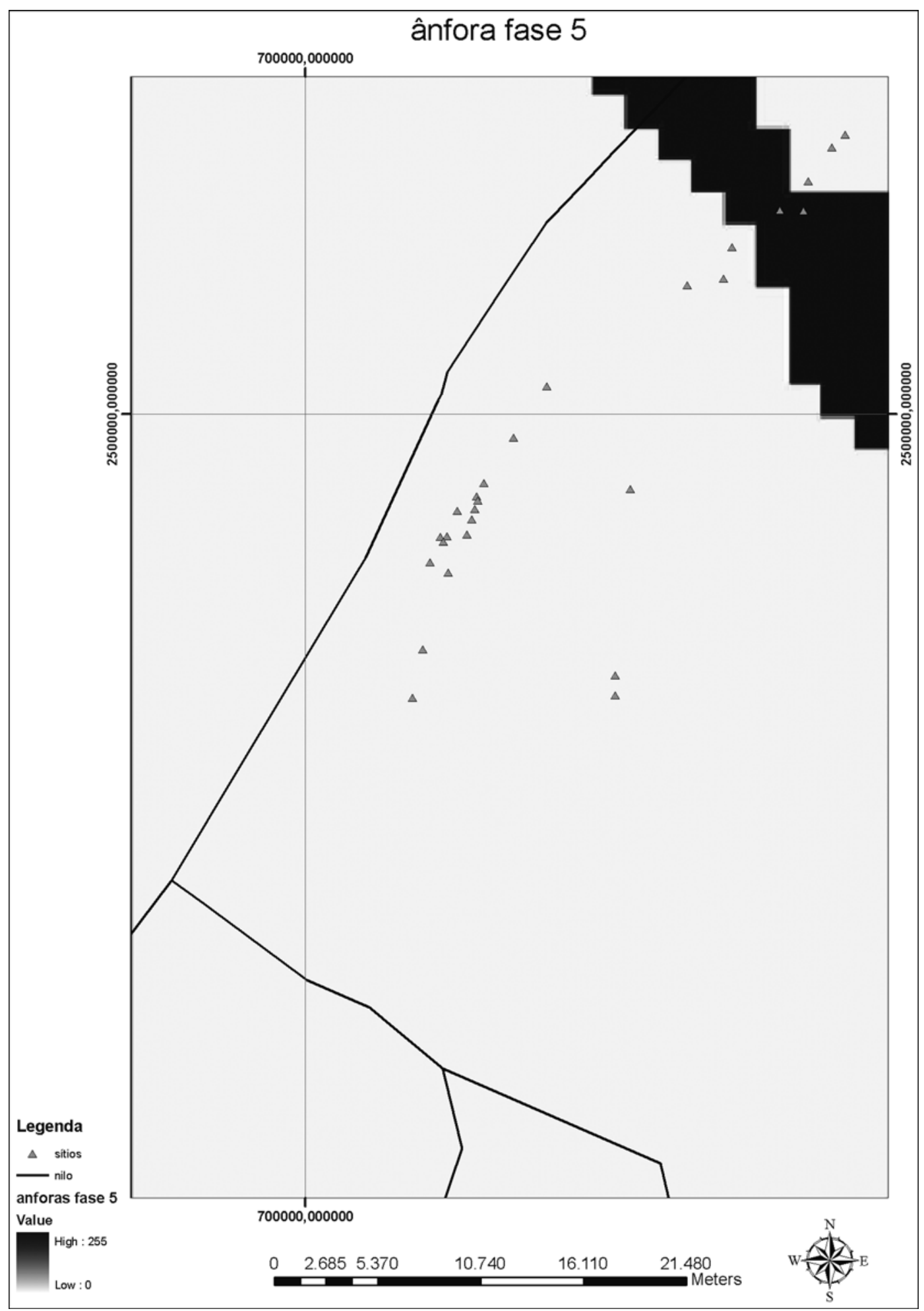


PELLINI, J.R. O uso do GIS para entender o sistema de trocas no Egito Antigo e na Núbia: mapas de circulação, uma nova abordagem para as superfícies de custo. Rev. do Museu de Arqueologia e Etnologia, São Paulo, 15-16: 209-245, 2005-2006.

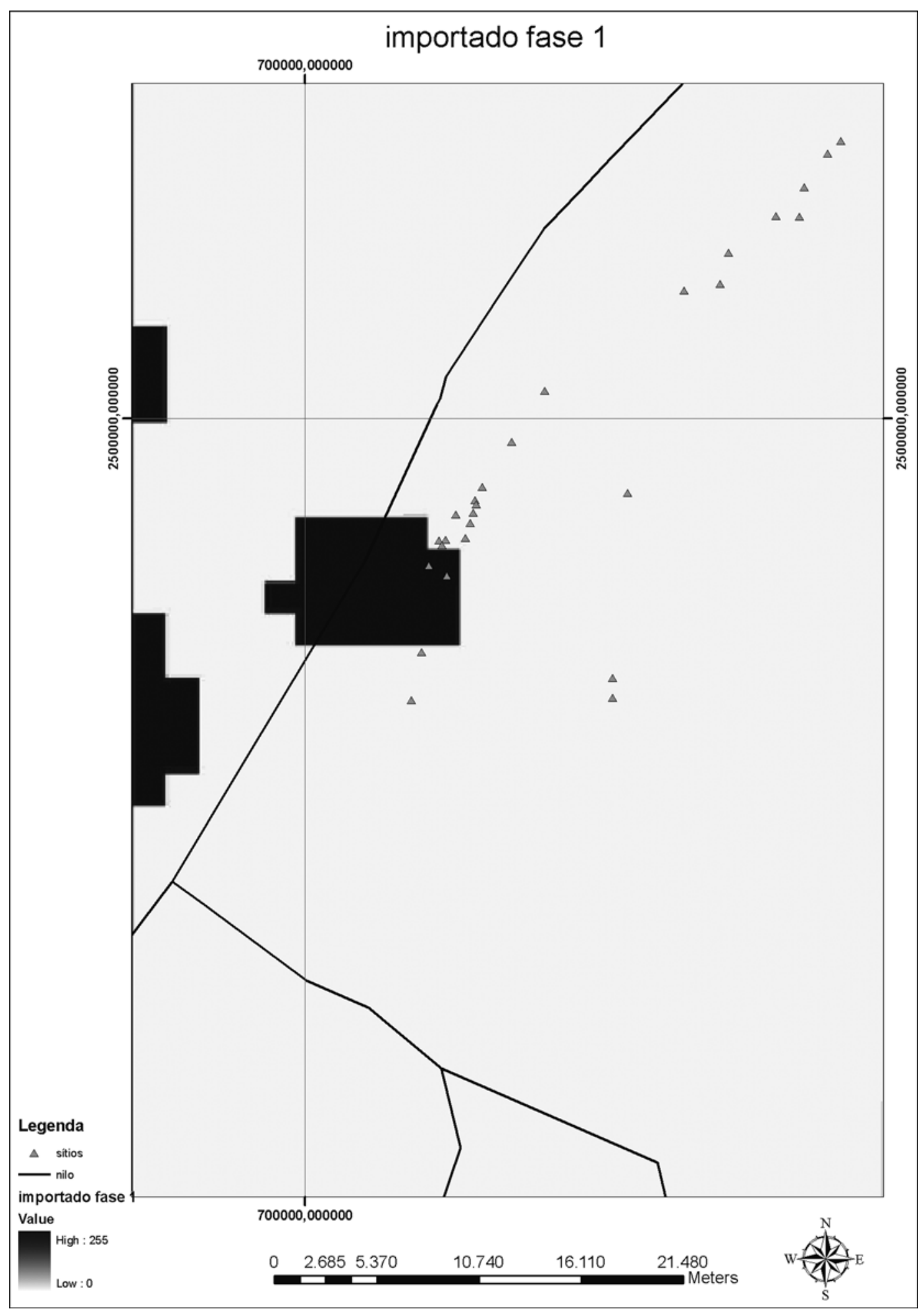


PELLINI, J.R. O uso do GIS para entender o sistema de trocas no Egito Antigo e na Núbia: mapas de circulação, uma nova abordagem para as superfícies de custo. Rev. do Museu de Arqueologia e Etnologia, São Paulo, 15-16: 209-245, 2005-2006.

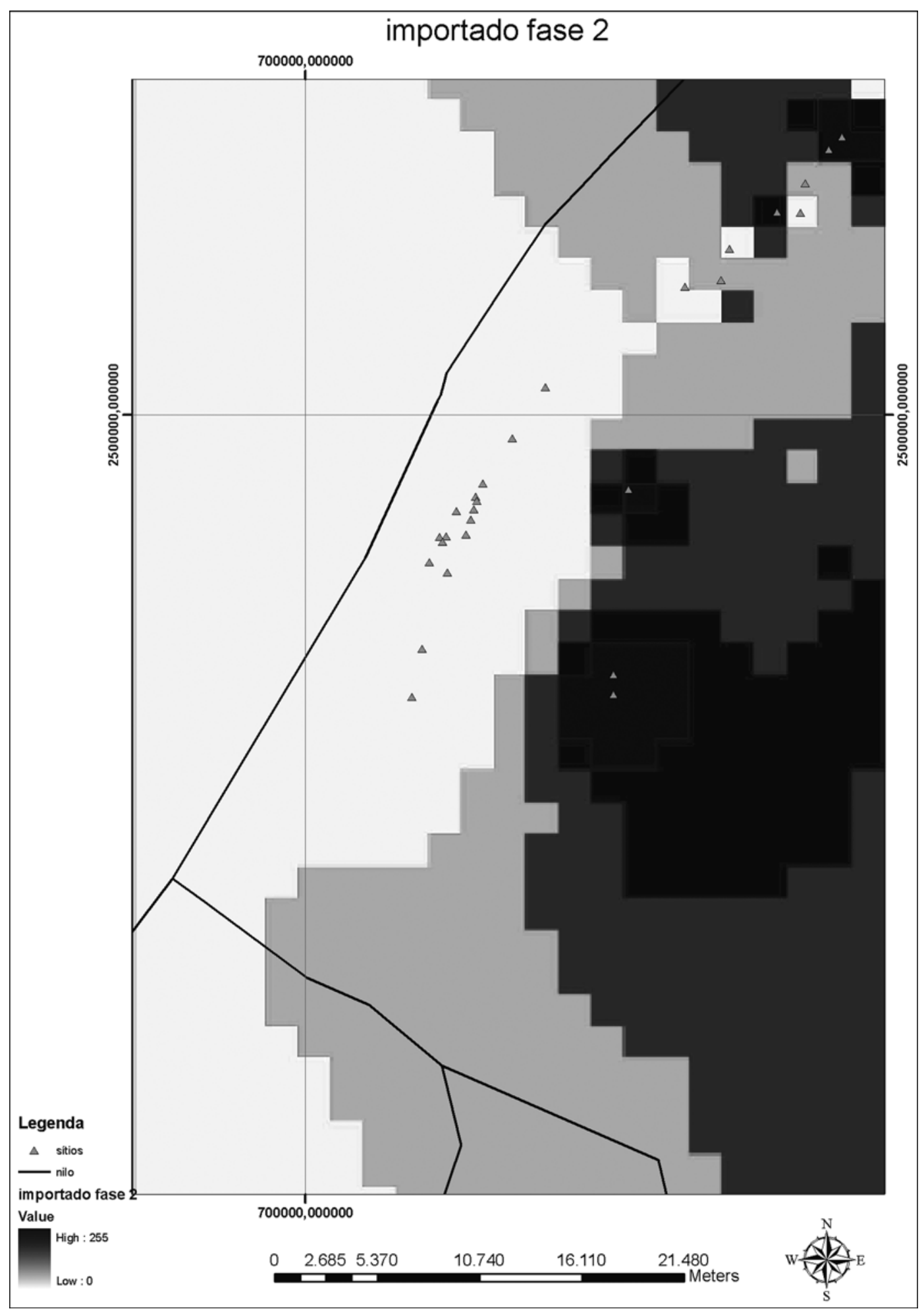




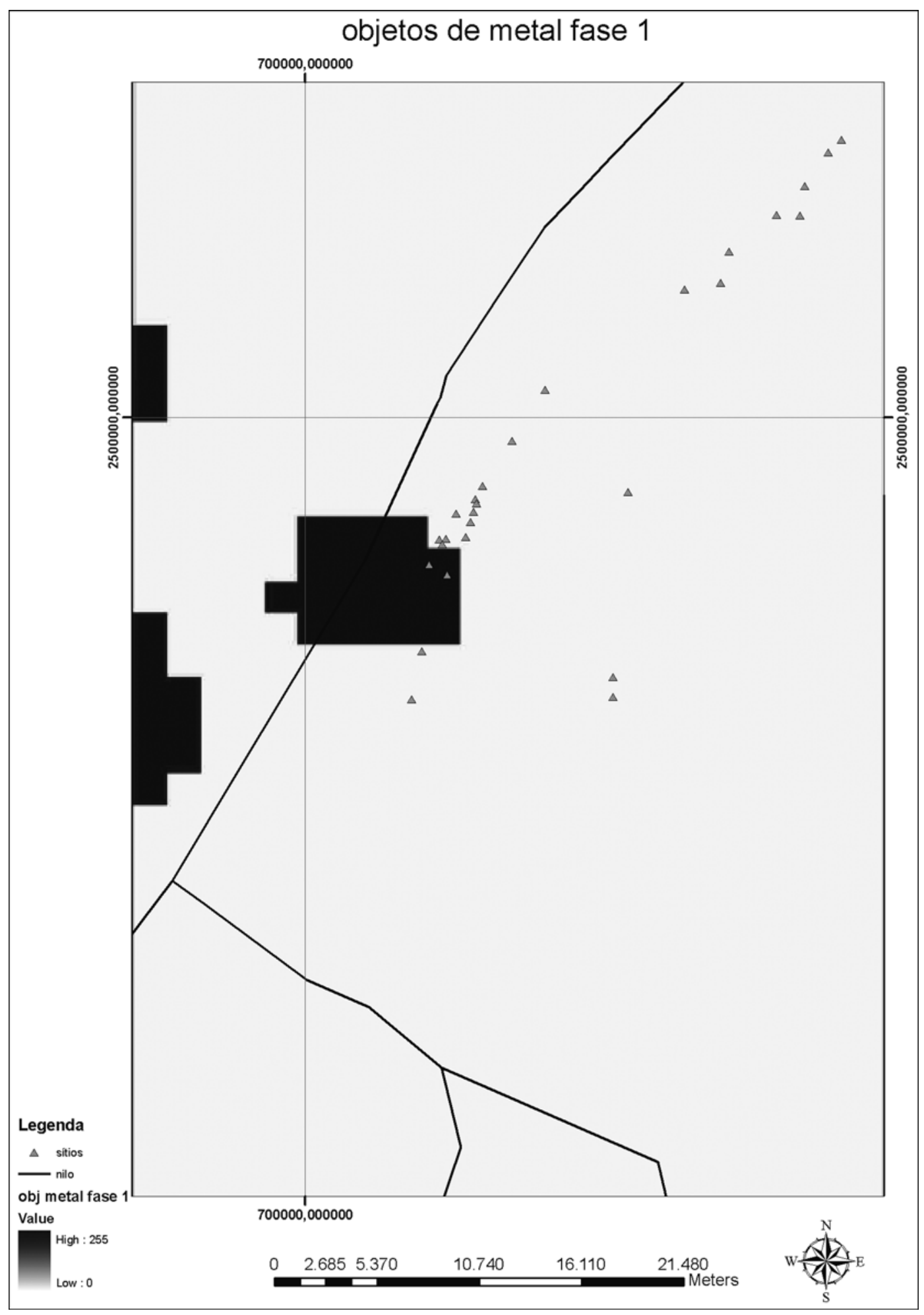


PELLINI, J.R. O uso do GIS para entender o sistema de trocas no Egito Antigo e na Núbia: mapas de circulação, uma nova abordagem para as superfícies de custo. Rev. do Museu de Arqueologia e Etnologia, São Paulo, 15-16: 209-245, 2005-2006.

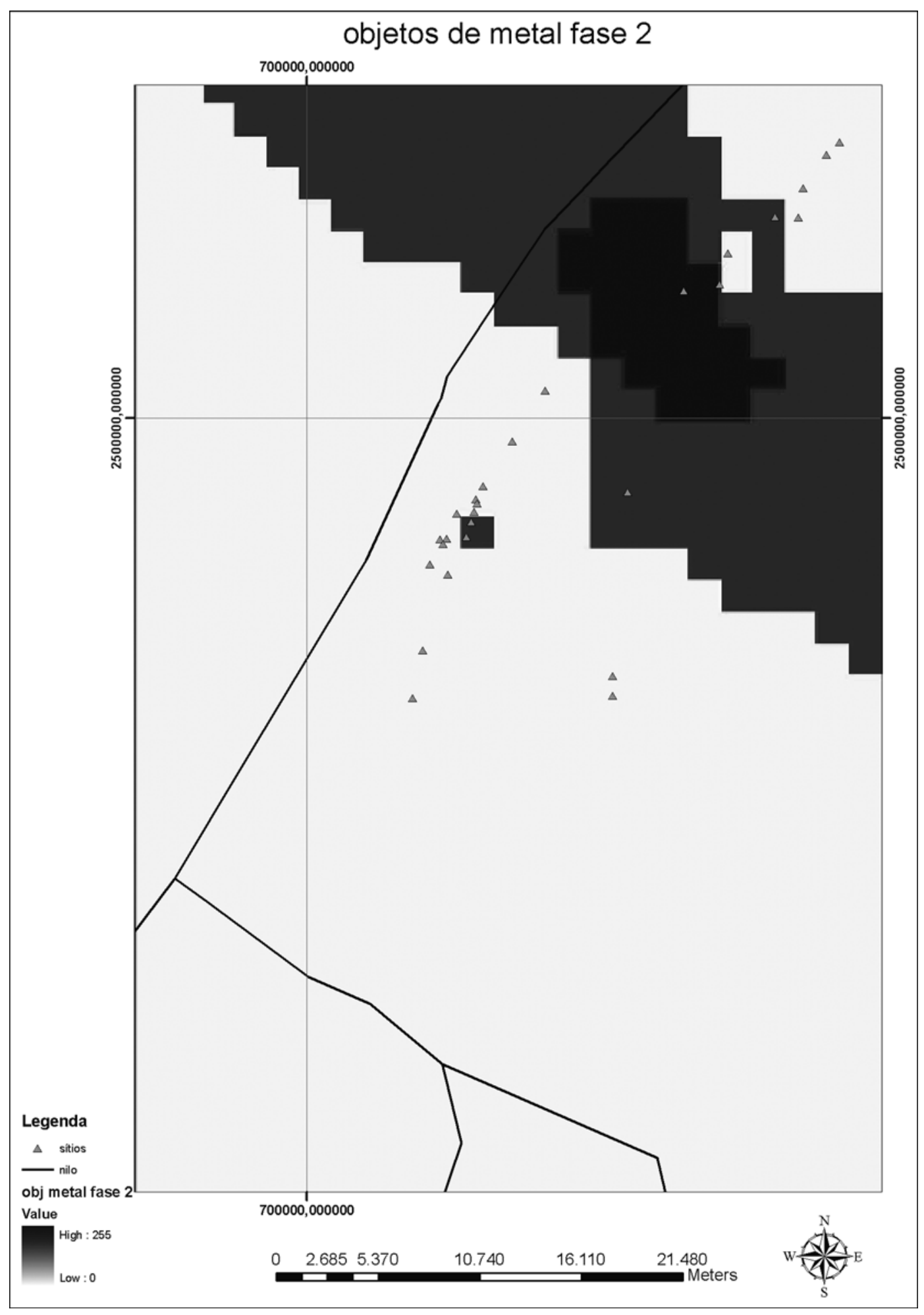


PELLINI, J.R. O uso do GIS para entender o sistema de trocas no Egito Antigo e na Núbia: mapas de circulação, uma nova abordagem para as superfícies de custo. Rev. do Museu de Arqueologia e Etnologia, São Paulo, 15-16: 209-245, 2005-2006.

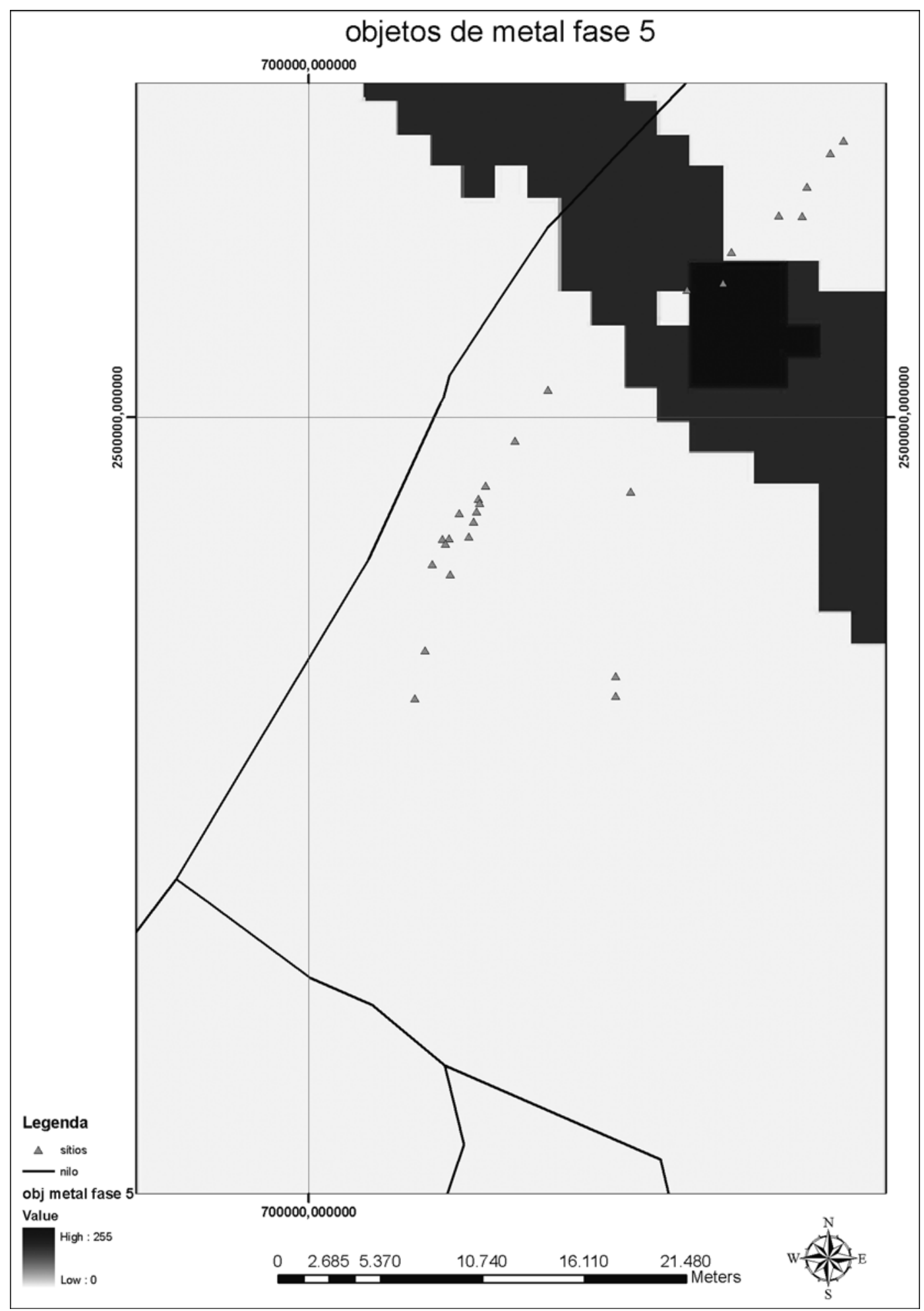


PELLINI, J.R. O uso do GIS para entender o sistema de trocas no Egito Antigo e na Núbia: mapas de circulação, uma nova abordagem para as superfícies de custo. Rev. do Museu de Arqueologia e Etnologia, São Paulo, 15-16: 209-245, 2005-2006.

abrangência e de maneira mais intensa. Na Fase V, embora ambos percam intensidade e abrangência, continuam circulando e mantendo a mesma estrutura de interação.

Mudando um pouco nosso foco de atenção dos objetos, para as fábricas cerâmicas, veremos mais claramente as estruturas de circulação existentes na área analisada. As fábricas do tipo I, utilizadas normalmente para a confecção de objetos cerâmicos de uso doméstico, eram constituídas de argilas aluviais, de fácil obtenção. Estas fábricas eram produzidas localmente. Se observarmos o mapa de circulação destas fábricas, veremos que elas circulam tanto na Fase I quanto na fase II, por toda a área e com bastante intensidade, ou seja, ela se movimentam por todo o sistema. Comparando estes mapas com os mapas confeccionados paras as fábricas do tipo II e III, que são geralmente associadas às fábricas de uso mais restrito e de obtenção não tão fácil, podemos observar que apenas a fábrica tipo II, na Fase II, é que apresenta uma circulação um pouco maior, em todos os outros casos a circulação é bem restrita e pontual. No caso das fábricas do tipo IV, associadas aos objetos cerâmicos importados, vemos que embora circulem na Fase I, circulam com muito pouca intensidade. Já na Fase II aumenta um pouco a intensidade de circulação mas não a abrangência. Por fim, na Fase V, este tipo de fábrica passa a não mais figurar no sistema de circulação. Neste caso as implicações são claras. Ao que parece, parte dos objetos que eram importados e confeccionados com este tipo de fábrica passa a ser confeccionado com argilas locais.

\section{Conclusão}

Durante o Segundo Período Intermediário, a grande confluência cultural entre os povos do Grupo C, kushitas e egípcios, resulta praticamente no desaparecimento das antigas culturas nativas e na assimilação do modo de vida egípcio. Este fato é bem evidenciado na cerâmica, que deixa de apresentar formas tradicionais locais e passa a apresentar, tanto na forma quanto na decoração, características egípcias. Este fenômeno se estende também para as práticas funerárias ao ponto de, como afirma Williams (1992), ser muito difícil distinguir um enterramento núbio e um enterramento egípcio durante o Novo Império. Então nos perguntamos como diferenciar um enterramento egípcio de um enterramento núbio? Para Save-Soderbergh (1990), a resposta é simples. Deve-se procurar não o que está presente no mobiliário funerário, mas o que está faltando. Tanto nos sítios de Qustul, Adindan e parte de Serra, como em geral nos cemitérios escavados pela SJE, pudemos ver através da análise estatística do material que o que falta no mobiliário funerário são identificações que remetam aos mortos enterrados. Embora todo o conjunto arquitetônico das tumbas assuma uma forma egípcia, embora as características como posição do corpo, mobiliário funerário, também assumam formas egípcias, a falta de objetos como estelas e ushabitis, que servem para identificar o morto, são um forte indicativo de que estes enterramentos não são de egípcios. De acordo com as crenças religiosas egípcias, seria impensável ser enterrado e não ser identificado. Em cemitérios nas proximidades de centros administrativos como Soleb e Buhen, são encontrados enterramentos egípcios com a devida identificação dos mortos. O que os cemitérios que analisamos demonstram é que ali foram enterrados núbios que assumiram a cultura egípcia, mas não assimilaram todo o caráter ideológico de algumas práticas como a funerária.

No caso da política, com a reconquista da Núbia, surge a questão do verdadeiro papel egípcio na região. Os antigos centros administrativos são reconstruídos e novos fortes são instalados na área. Mas qual o papel dos egípcios na Núbia: colonização, exploração, reafirmação da divindade real do governo egípcio, ou uma política de benefício mútuo? A resposta pode ser encontrada, pelo menos na fase inicial da $18^{a}$ dinastia, na grande liberdade política e econômica exercida pelo principado de Teh Khet, localizado entre os distritos de Debeira e Serra. Segundo Smith (1976), o principado foi deixado sob o controle dos príncipes locais, sendo que a maioria do setor burocrático era formada por membros de famílias locais. A administração egípcia funcionava em uma esfera mais elevada, principalmente no que se refere à manutenção da ordem local. A nosso ver, a política egípcia para a Núbia incluía uma dominação política e territorial forte, mas que visava um equilíbrio mútuo na área, que gerava benefícios para ambos os lados. Não podemos 
PELLINI, J.R. O uso do GIS para entender o sistema de trocas no Egito Antigo e na Núbia: mapas de circulação, uma nova abordagem para as superfícies de custo. Rev. do Museu de Arqueologia e Etnologia, São Paulo, 15-16: 209-245, 2005-2006.

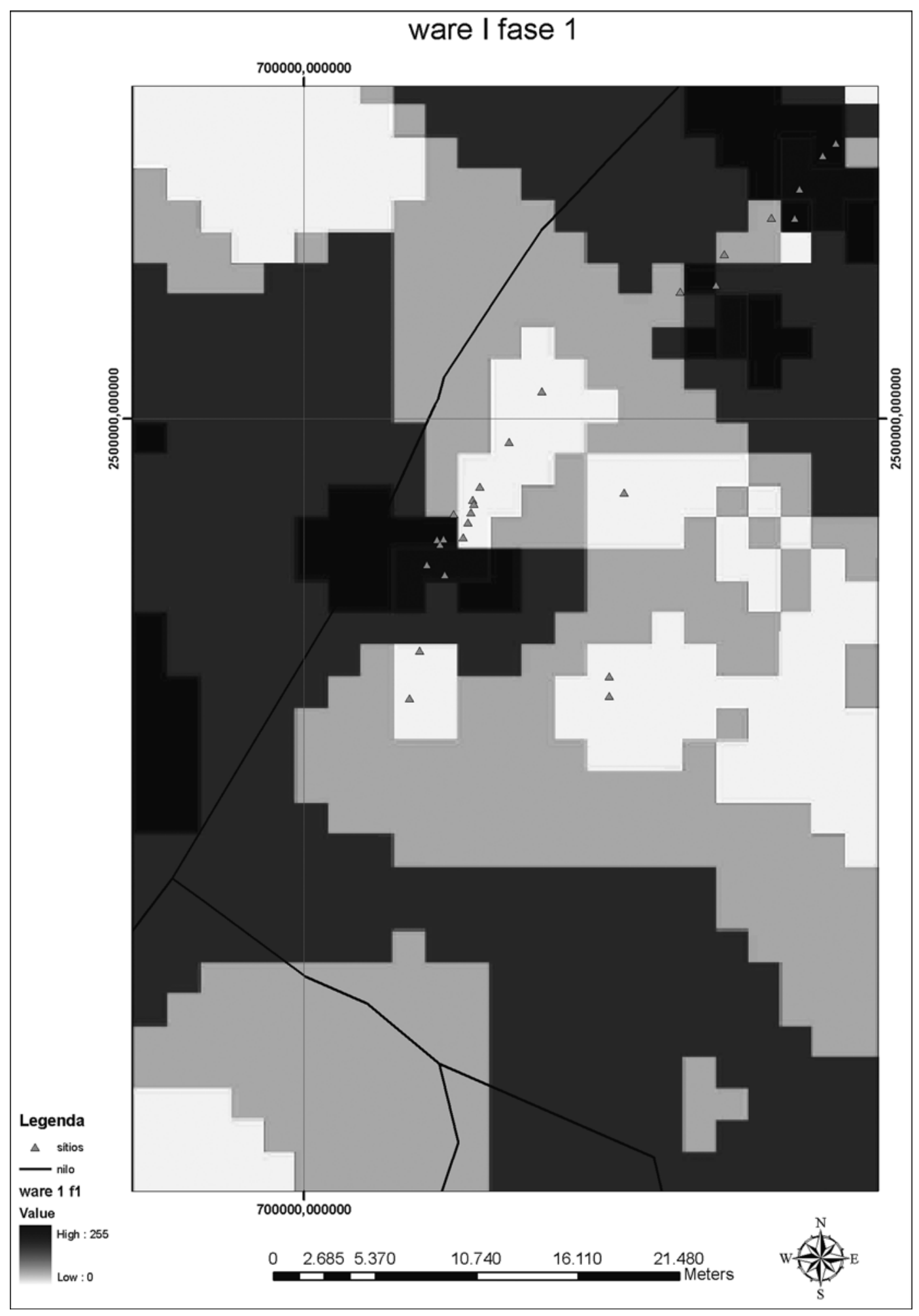


PELLINI, J.R. O uso do GIS para entender o sistema de trocas no Egito Antigo e na Núbia: mapas de circulação, uma nova abordagem para as superfícies de custo. Rev. do Museu de Arqueologia e Etnologia, São Paulo, 15-16: 209-245, 2005-2006.

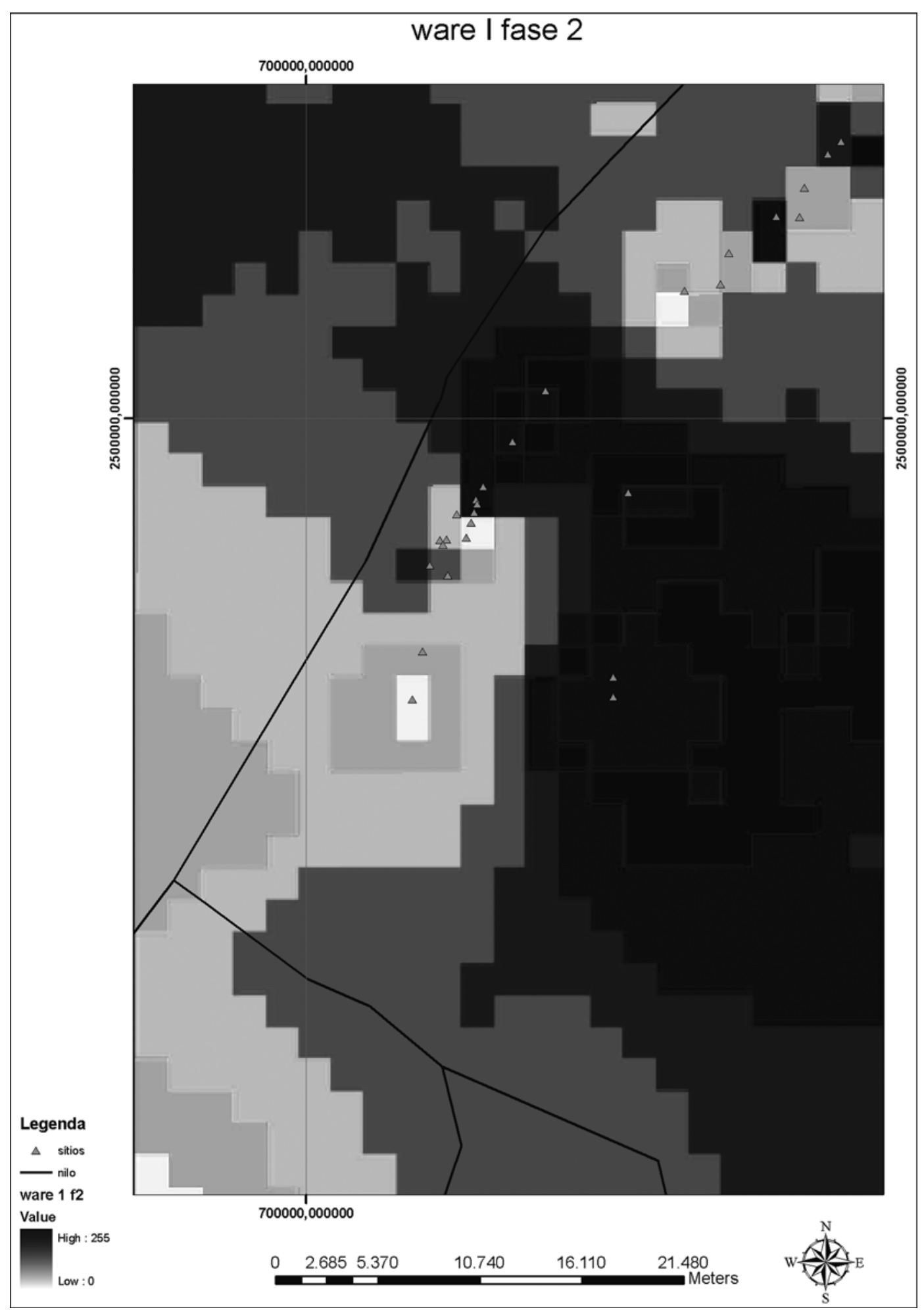


PELLINI, J.R. O uso do GIS para entender o sistema de trocas no Egito Antigo e na Núbia: mapas de circulação, uma nova abordagem para as superfícies de custo. Rev. do Museu de Arqueologia e Etnologia, São Paulo, 15-16: 209-245, 2005-2006.

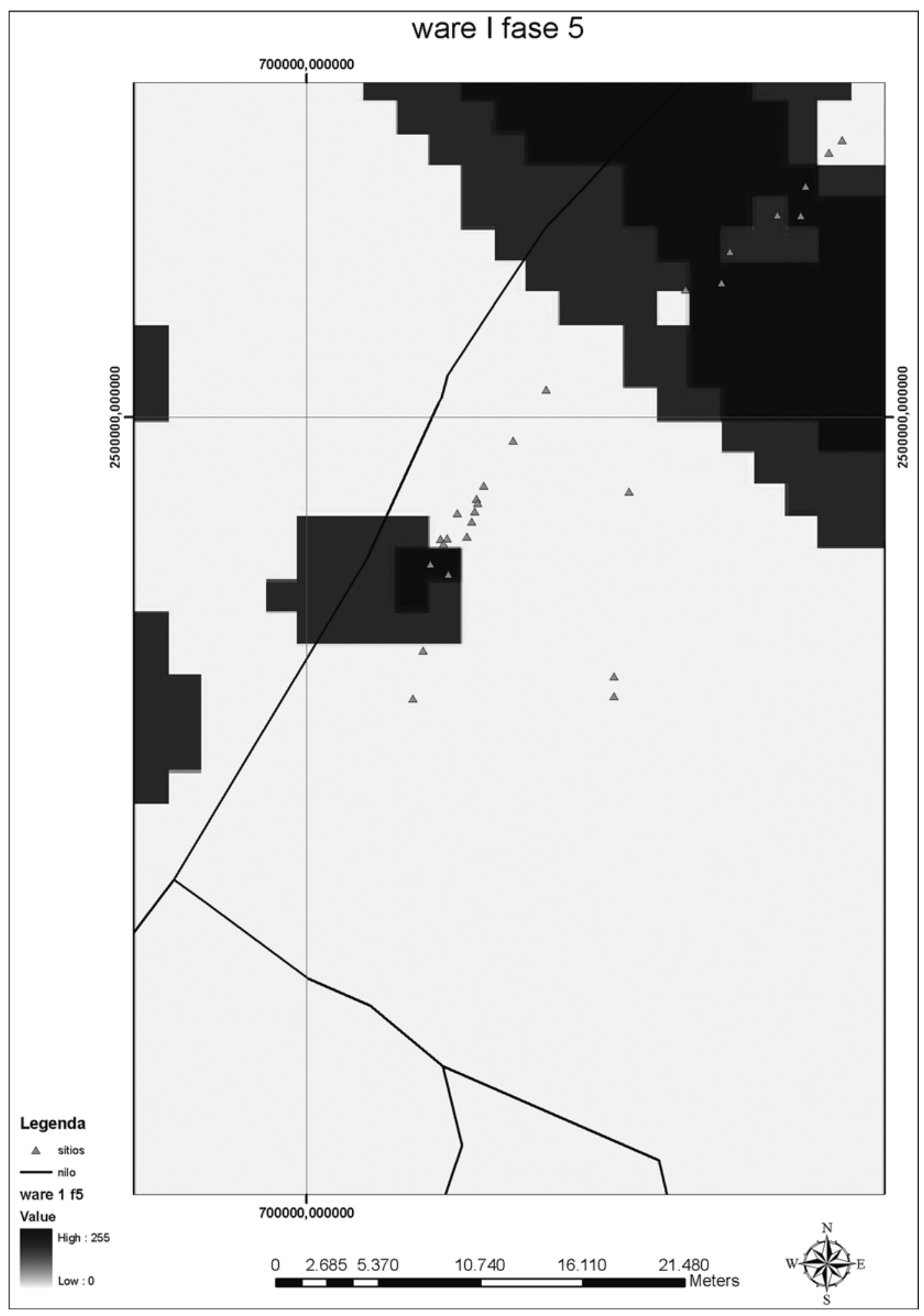


PELLINI, J.R. O uso do GIS para entender o sistema de trocas no Egito Antigo e na Núbia: mapas de circulação, uma nova abordagem para as superfícies de custo. Rev. do Museu de Arqueologia e Etnologia, São Paulo, 15-16: 209-245, 2005-2006.

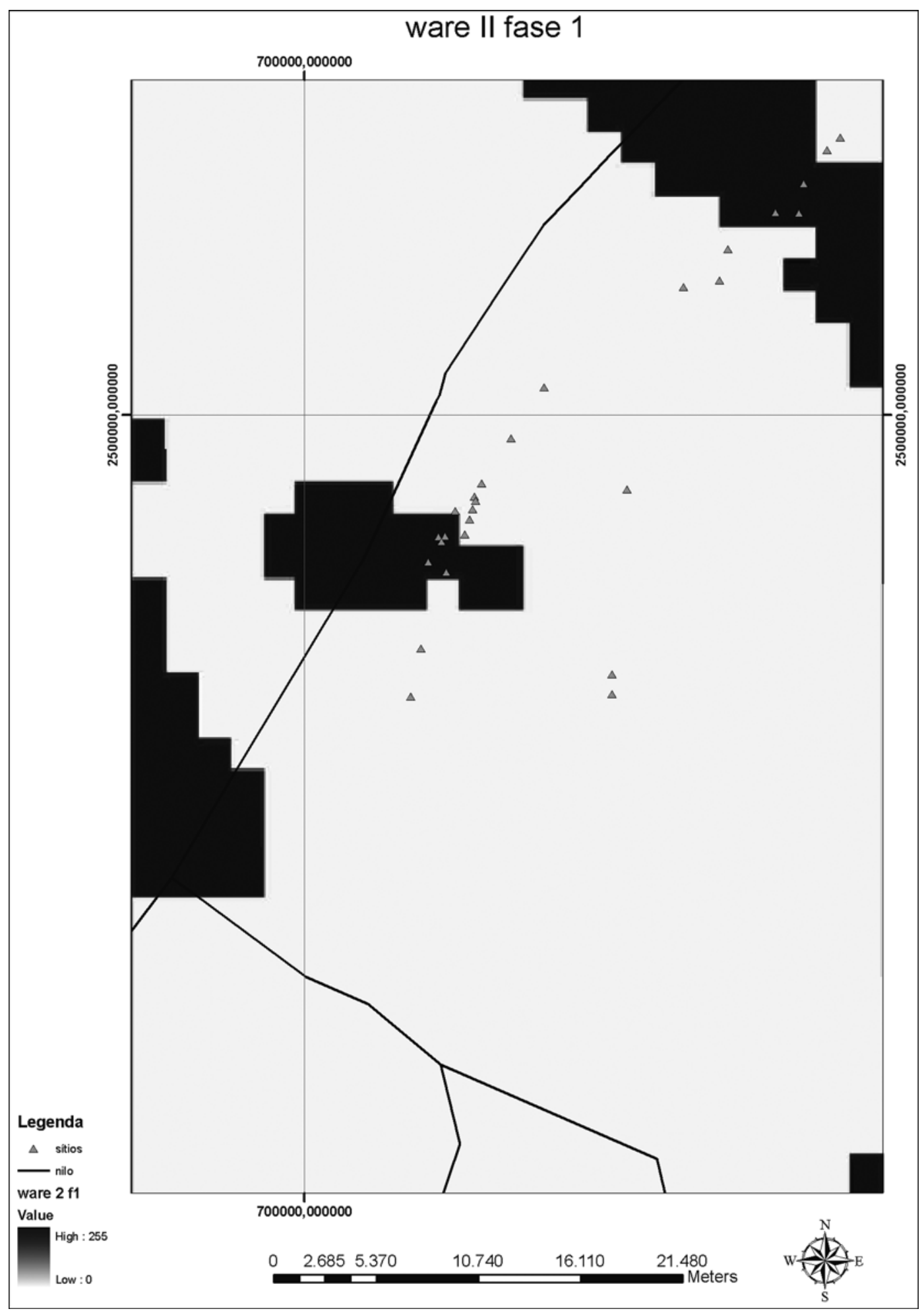


PELLINI, J.R. O uso do GIS para entender o sistema de trocas no Egito Antigo e na Núbia: mapas de circulação, uma nova abordagem para as superfícies de custo. Rev. do Museu de Arqueologia e Etnologia, São Paulo, 15-16: 209-245, 2005-2006.

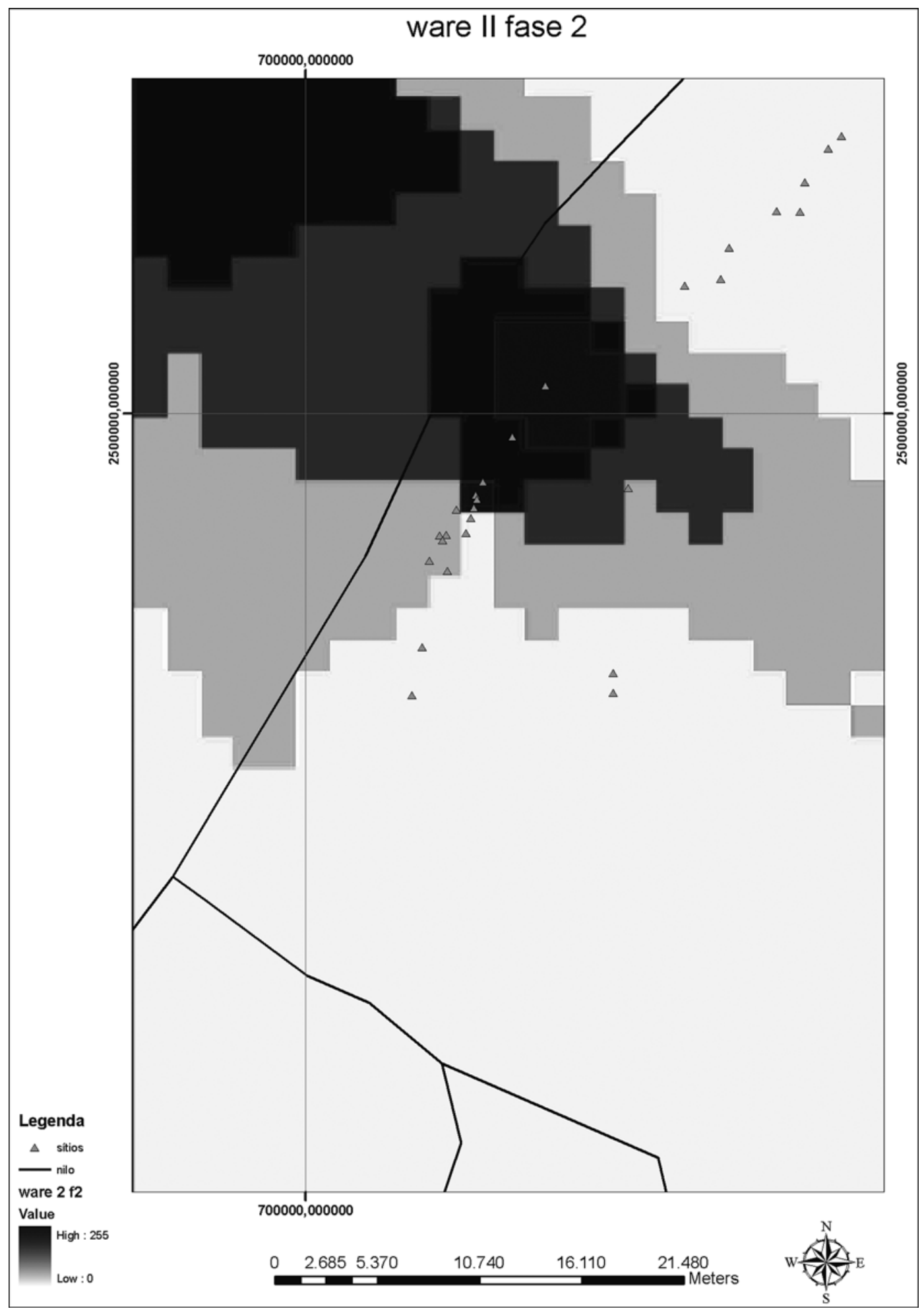


PELLINI, J.R. O uso do GIS para entender o sistema de trocas no Egito Antigo e na Núbia: mapas de circulação, uma nova abordagem para as superfícies de custo. Rev. do Museu de Arqueologia e Etnologia, São Paulo, 15-16: 209-245, 2005-2006.

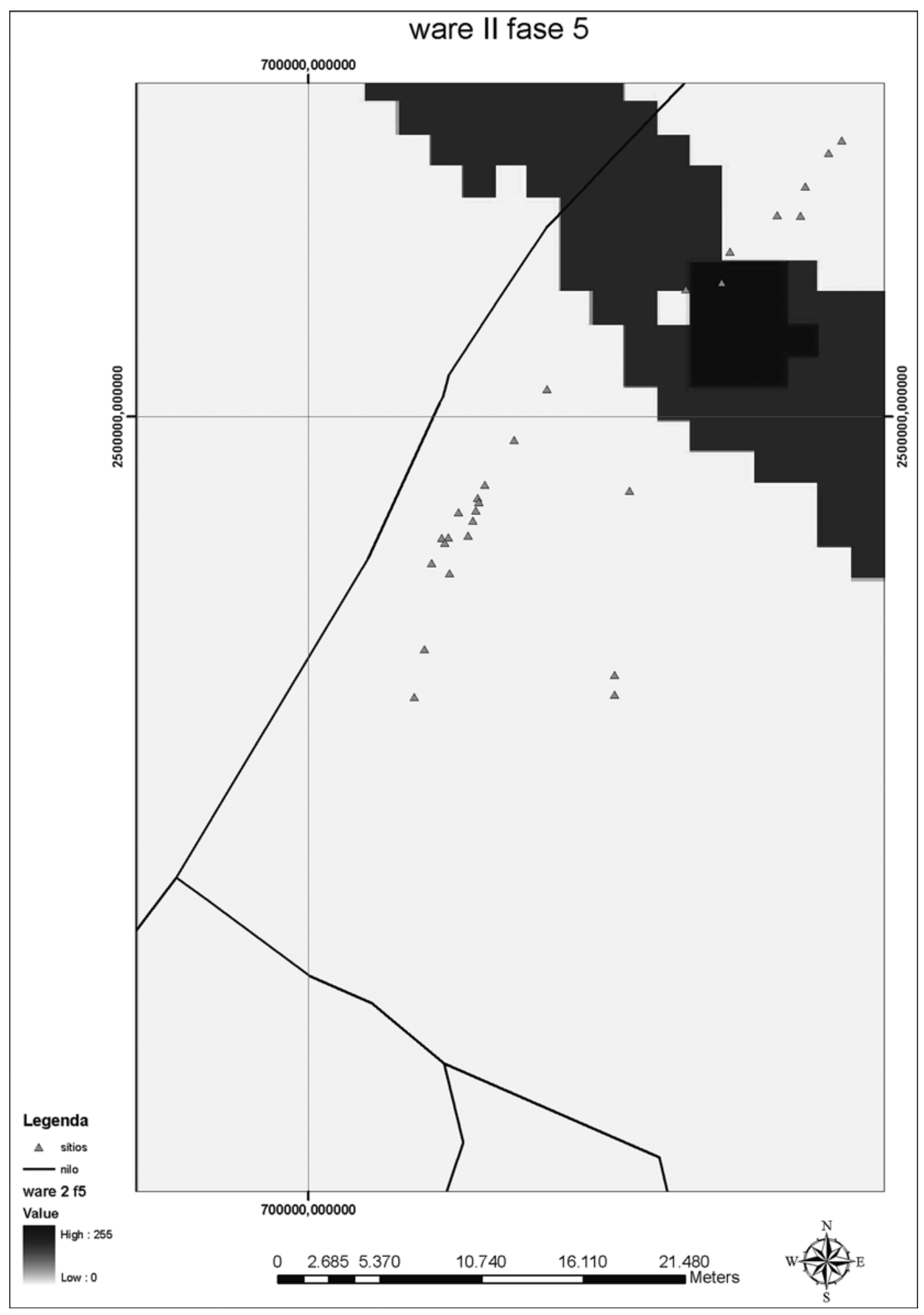


PELLINI, J.R. O uso do GIS para entender o sistema de trocas no Egito Antigo e na Núbia: mapas de circulação, uma nova abordagem para as superfícies de custo. Rev. do Museu de Arqueologia e Etnologia, São Paulo, 15-16: 209-245, 2005-2006.

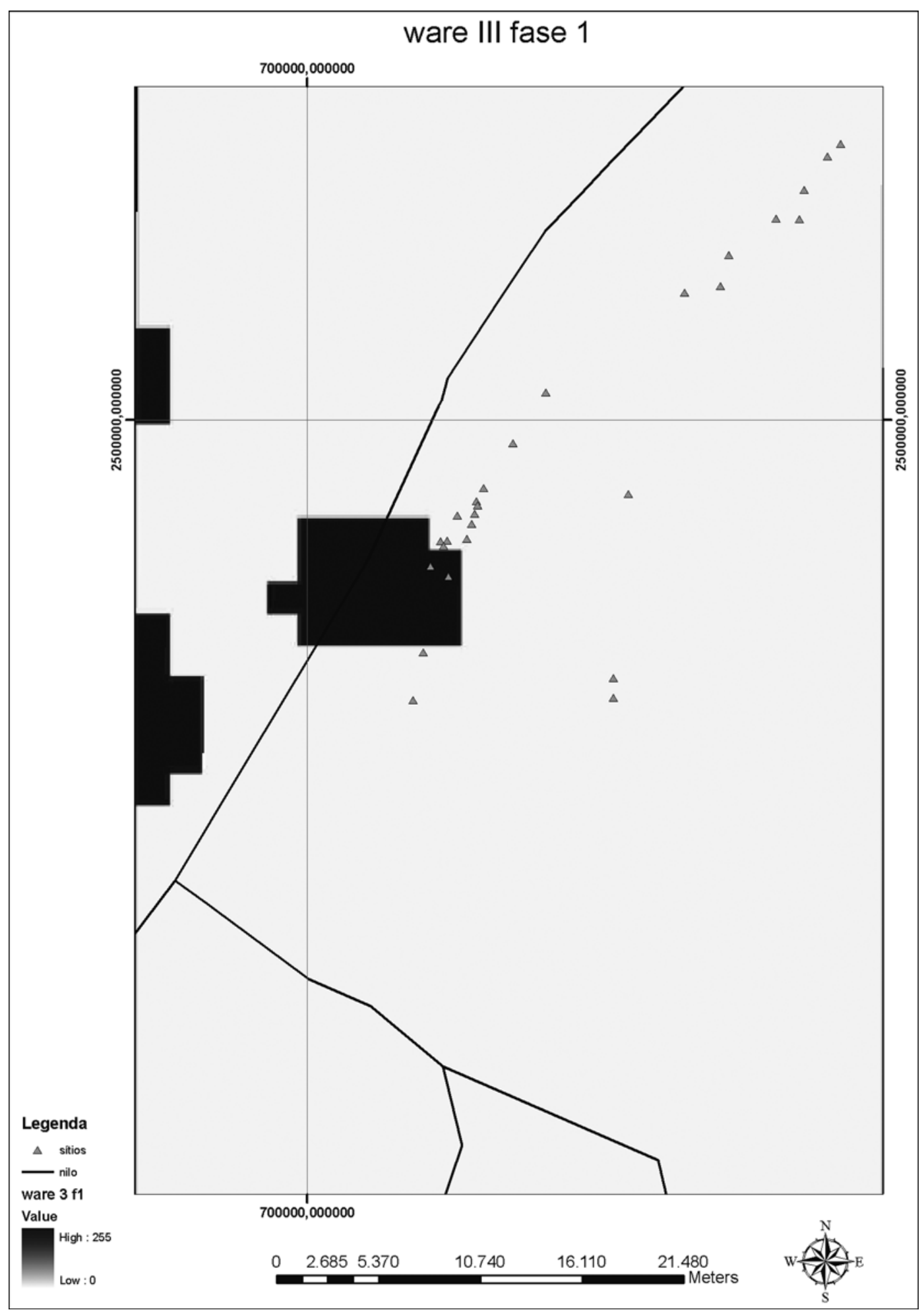


PELLINI, J.R. O uso do GIS para entender o sistema de trocas no Egito Antigo e na Núbia: mapas de circulação, uma nova abordagem para as superfícies de custo. Rev. do Museu de Arqueologia e Etnologia, São Paulo, 15-16: 209-245, 2005-2006.

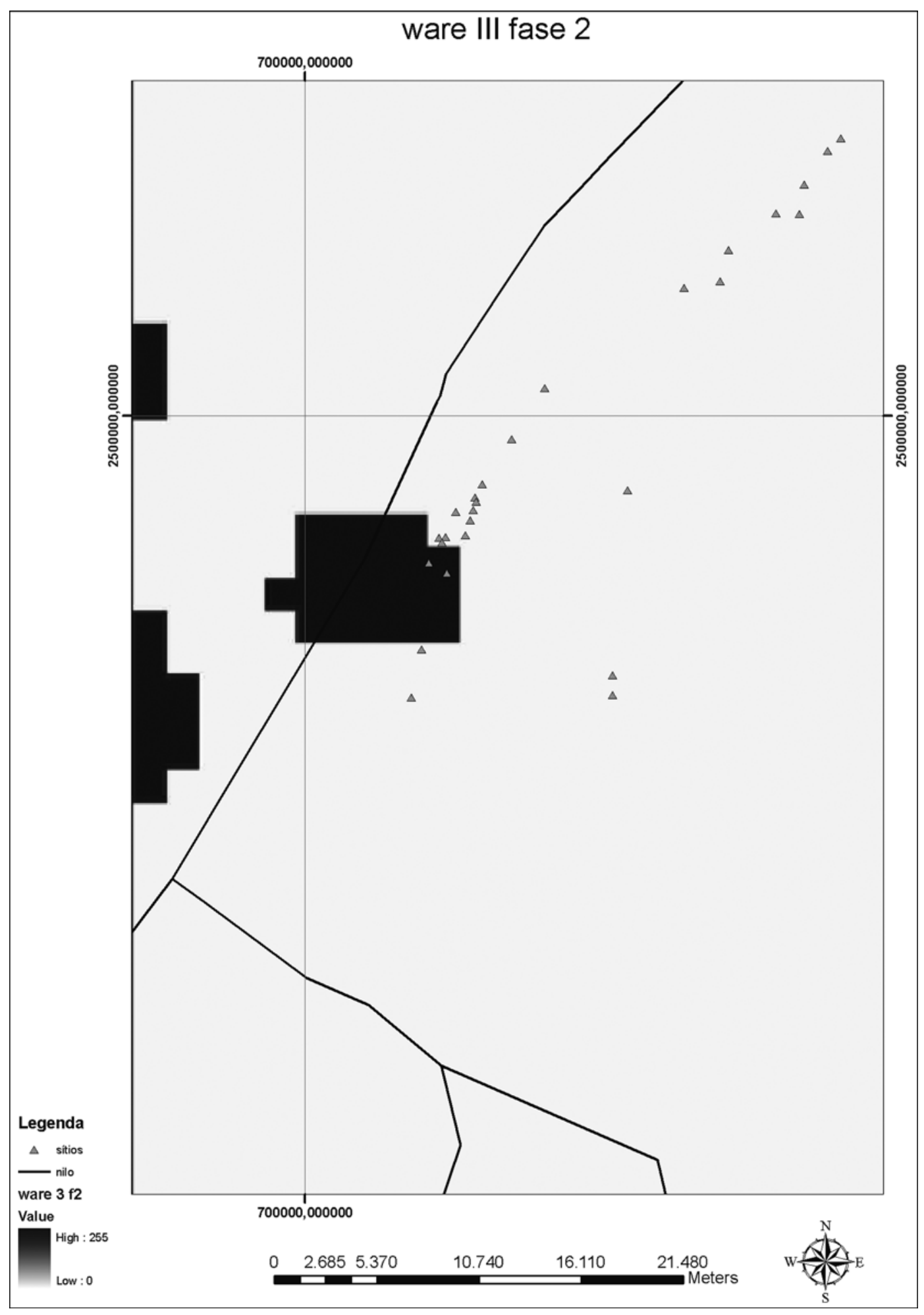


PELLINI, J.R. O uso do GIS para entender o sistema de trocas no Egito Antigo e na Núbia: mapas de circulação, uma nova abordagem para as superfícies de custo. Rev. do Museu de Arqueologia e Etnologia, São Paulo, 15-16: 209-245, 2005-2006.

entender a reconquista da Núbia e o papel exercido pelos egípcios baseando-nos apenas em um aspecto ou outro. É na realidade, uma gama enorme de fatores, políticos, econômicos, ideológicos e religiosos que dirigem as ações egípcias. Mas como esta política se refletia na estrutura econômica vigente na área?

A eventual liberdade que os governantes locais possuíam fazia com que as pessoas diretamente ligadas ao aparelho do estado usufruíssem certas regalias, como por exemplo, o acesso a produtos importados do Egito. Como afirmou Save-Soderbergh (1990), a Fase I de ocupação de Fadrus, é caracterizada por uma grande e generosa distribuição de valor, que fazia com que a classe dirigente e parte da classe média tivessem acesso direto a bens de prestígio e status. Esta liberdade e esta riqueza se traduzem em nosso material pela grande presença de ânforas, jarros de vinho e objetos importados e de metal ao longo das Fases I e II de ocupação dos cemitérios. Através de gráficos de regressão confeccionados por fase de ocupação, após o término da Fase II, ocorre um declínio da riqueza imobilizada nas tumbas. Isto é um reflexo direto da política egípcia, que durante a segunda metade da $18^{a}$ dinastia substitui a antiga classe dirigente local por burocratas egípcios. Este ato resulta na fragmentação e na redução significativa da classe dirigente local. Ao mesmo tempo, há uma gradativa mudança dos centros administrativos na direção de Dongola, mais ao sul. Esta mudança do eixo de gravidade política mais para o sul leva ao enfraquecimento da economia local dos antigos centros administrativos, que perdem seu papel de importância na administração da região. O reflexo desta mudança pode ser observado nos cemitérios que analisamos. Na Fase IV e V de ocupação, não há mais itens importados entre o material funerário. Há também neste período um aumento significativo dos itens de uso doméstico e de confecção local, resultado do desaparecimento da antiga classe dirigente e do aumento de enterramentos nestes cemitérios de membros da classe mais baixa. Ao mesmo tempo, as ânforas na Fase III, IV e V passam a se correlacionar com um número maior de objetos. O interessante é notar que as fábricas do tipo III, associadas principalmente às ânforas, têm nestas fases uma circulação muito reduzida, como foi evidenciado no mapa de circulação das fábricas do tipo III para a Fase V. Esta aparente incongruência é um claro indício de que a maioria das ânforas das Fases IV e V, não são ânforas confeccionadas com fábricas importadas mas sim com fábricas locais do tipo I.

Com estas mudanças as estruturas de circulação de produtos se alteram. A intensidade da circulação cai de modo geral. Há uma maior circulação de objetos de uso cotidiano e de itens utilitários e a redução quase completa da circulação de itens de valor, como metais, ânforas, jarros de vinho e objetos importados. Em nossos mapas de circulação estes itens, nas Fases I, II e V, sempre aparecem com uma circulação restrita e pontual. Com a mudança do centro administrativo de Farás para Soleb durante o reinado de Tutankamum, a região de Farás, onde se localizam os sítios estudados, passa a sofrer um colapso que resultará praticamente no desaparecimento da população da área. Um dos fatores que apoiam esta idéia é o fato de não encontrarmos sítios do período ramessida na região de Farás (Williams 1992).

Como vimos nos mapas de circulação, os objetos de uso cotidiano possuem uma circulação mais abrangente e intensa, como pode ser observado no caso dos jarros e tigelas. Ao longo de todas as fases analisadas, jarros e tigelas sempre apresentaram índices de correlação semelhantes o que é em parte refletido nos mapas de circulação. Neste sentido, não seria difícil imaginar que estes itens fariam parte de um mesmo circuito de distribuição, ficando restritos à área do circuito de distribuição número 3 (Pellini 2005). Este circuito é um circuito mais regional, onde a rede de distribuição tende a ficar centrada localmente. A circulação destes produtos poderia operar dentro de um sistema de reciprocidade. Neste caso, a grande quantidade de interações em série, típica dos sistemas de reciprocidade, se traduz em uma abrangência espacial sem grandes picos de concentração. Em nossos mapas de circulação o sistema de reciprocidade pode ser percebido onde há o predomínio de áreas com muitas gradações de tons de preto e cinza.

No que se refere aos jarros carenados, jarros de estocagem e suportes, os mapas de circulação sugerem que estes poderiam circular dentro de um sistema de redistribuição. Isto porque nestes casos, ao mesmo tempo em que temos uma certa abrangência espacial, ela se apresenta com 
PELLINI, J.R. O uso do GIS para entender o sistema de trocas no Egito Antigo e na Núbia: mapas de circulação, uma nova abordagem para as superfícies de custo. Rev. do Museu de Arqueologia e Etnologia, São Paulo, 15-16: 209-245, 2005-2006.

intensidade focal, ou seja, com picos de concentração. A nosso ver, a analogia deste tipo de estrutura com os sistemas de redistribuição é clara, pois poderíamos pensar que os produtos são concentrados em um dado local e distribuídos ao redor.

Em relação às ânforas, objetos importados, jarros de vinho, objetos de metal e objetos de pedra, embora os mapas de circulação apresentem pequenas variações entre a circulação destes objetos, principalmente em relação às ânforas, fica claro que formam um grupo relativamente coeso. A grande diferença entre eles se dá, a nosso ver, em relação aos circuitos de distribuição e não ao sistema de troca. As análises de correlação efetuadas apontam um índice de correlação semelhante entre os objetos de metal e os objetos de pedra, mas diferente dos índices de correlação obtidos para as ânforas, jarros de vinho e objetos importados. Como estes objetos apresentam uma distribuição parecida, mas um índice de correlação diferente, a nossa sugestão é que embora participassem do mesmo sistema de circulação chegavam à área dos sítios através de circuitos de distribuição diferentes. Os objetos de metal e os objetos de pedra possivelmente utilizavam as rotas do deserto, principalmente circuitos 1 e 2 e os demais itens utilizavam as rotas do Nilo. Este tipo de sistema se traduz espacialmente em uma circulação não tão abrangente e com pontos de concentração bem direcionados. A diferença entre este sistema e o sistema de redistribuição é que a área ao redor dos pontos de concentração é muito pequena ou inexistente.

Com os dados obtidos ao longo de todo este trabalho, temos uma visão mais clara de como operava o sistema de trocas e de circulação no Egito durante o Novo Império. A nosso ver dois sistemas básicos estavam em operação: um sistema que resultava em uma circulação difusa e generalizada dos bens; e um outro sistema que resultava em uma circulação focada e direcionada dos bens. No primeiro sistema circulam preferencialmente objetos ordinários e de uso cotidiano. Já no segundo sistema circulam objetos importados e de luxo. Nas áreas onde se observa a presença de uma circulação difusa, temos um sistema de circulação direta, ou seja, os membros de cada unidade econômica viajam para outras localidades a fim de adquirirem os produtos de que necessitam, sendo assim, os residentes de cada localida- de têm de se locomover a inúmeros locais para satisfazer suas necessidades, o que gera um aumento na distância percorrida e assim um aumento no custo das transações. Em um sistema de distribuição direto, como por exemplo a reciprocidade, em um número de pontos de produção $(\mathrm{N})$, cada produtor teria a necessidade de visitar ou ser visitado por ( $\mathrm{N}$ - 1) representantes de outras localidades para que uma distribuição total operasse, com uma conseqüente jornada expressa por $\mathrm{N}(\mathrm{N}-1) / 2$. Em sistemas como este temos uma grande quantidade de interações entre indivíduos, sendo assim, os objetos partem do ponto de origem e passam de mão em mão entre os indivíduos até chegar a seu destino final. Como uma grande quantidade de pessoas poderia estar envolvida nestas relações de troca, a manutenção das forças sociais coesas e as boas relações de vizinhança são um dos principais fatores de sustentação do sistema. Neste caso, como afirmou Janssen (1994: 135), todos são credores e devedores de muitos outros. Aqui a atuação da comunidade é vista como uma participação de grande generosidade e reciprocidade. Os indivíduos que se apresentam neste sistema para trocar são indivíduos morais.

Já nas áreas onde há uma circulação focal e direcionada os objetos partem da fonte de origem e seguem diretamente para seu destino sem um grande número de interações. Neste caso temos provavelmente movimentos de apropriação em direção a um centro e uma posterior distribuição a partir deste centro. Este é um exemplo de circulação indireta, onde produtos e serviços de fora da unidade econômica são adquiridos em algum local central, assim os indivíduos não necessitam viajar a diferentes lugares para obter os produtos que desejam. Em sistemas indiretos como a redistribuição ou sistemas de mercado, onde uma localidade funciona como um local central de distribuição, os habitantes das vilas ao redor terão que viajar somente uma vez, sendo que a jornada pode ser expressa apenas por $(\mathrm{N}-1)$.

Embora ainda reste muito a se fazer em relação ao que conhecemos dos sistemas de troca praticados no Egito Antigo do Novo Império, esperamos que esta pesquisa venha a fornecer uma contribuição, mesmo que pequena, para um melhor entendimento dos processos relativos às trocas de bens e serviços na antiguidade egípcia. 
PELLINI, J.R. O uso do GIS para entender o sistema de trocas no Egito Antigo e na Núbia: mapas de circulação, uma nova abordagem para as superfícies de custo. Rev. do Museu de Arqueologia e Etnologia, São Paulo, 15-16: 209-245, 2005-2006.

PELLINI, J.R. The use of GIS to understand the exchange systems in Ancient Egypt and Nubia: circulation maps, a new approach to cost surface analysis. Rev. do Museu de Arqueologia e Etnologia, São Paulo, 15-16: 209-245, 2005-2006.

ABSTRACT: In the last years cost surface analysis became part of exchange system studies. The basic problem with this GIS methodology is that the principles of analysis are based in modern economic theory and in the concept of economic rationality. This kind of analysis doesn't consider the social aspect of landscape. In my $\mathrm{PhD}$ dissertation, I considered a new approach to cost surface analysis based in social and physical cost raster. This cultural cost surface map was added with archaeological distribution maps. The final result I named as circulation maps.

UNITERMS: Ancient Egypt - GIS - Exchange systems - Trade.

\section{Referências bibliográficas}

BELL, T.; WILSON, A.; WICKHAM, A.

2002 Tracking the Samnites: Landscape and Comminicatios Routes in the Sangro Valley, Italy. American Journal of Archaeology, 106: 169-186.

BOURRIAU, J.

1997 Beyond Avaris: The Second Intermediate Period in Egypt Outside the Eastern Delta. E.D. Oren (Ed.) The Hyksos: New historical and archaeological perspectives. University Museum Monograph 96. University Museum Symposium Series 8. Philadelphia, The University Museum: 159-182.

1998 Egyptian Pottery Found in Kerma Graves. Actes de la IX Conference Internationale des Etudes Nubiennes. Boston, 21-26 aôut: 1-22.

BOURIAU, J.; NICHOLSON, P.

1992 Marl Clay Pottery Fabrics of the New Kingdom from Memphis, Saqqara and Amarna. Journal of Egyptian Archaeology, LXXVIII: 29-91.

CHISHOLM, M.

1962 Rural Settlement and Land Use. An Essay in Location. London: Hutchinson University Press.

CLARK, GR.

1965 Traffic in Stone Axe and Adze Blades. The Economic History Review, 18: 1-29.

DARNELL, J.; DARNELL, D.

1997 The Luxor-Frashut Desert Road Survey 19961997. Oriental Institute Annual Report.

1998 The Luxor-Frashut Desert Road Survey 19971998. Oriental Institute Annual Report.

GILLINGS, M.; WHEATLEY, D.

2002 Spatial Technology and Archaeology. The Archaeological Applications of GIS. London: Taylor and Francis.
GREENOUGH, J.; MALLORY-GREENOUGH, L.; OWEN, J.

1998 Provenance of Temper in a new Kingdom Egyptian Pottery Sherd: Evidence from the Petrology and Mineralogy of Basalt Fragments. Geoarchaeology, 13 (4): 391-410.

HASSAN, F.

1990 Town and Village in Ancient Egypt: Ecology, society and Urbanization. P. Robertshaw (Ed.) A History of African Archaeology. London, Portsmouth: 551-569.

HOPKINS, T.

1965 Sociology and the Substantive View of the Economy. K. Polanyi; C. Arensensberg; H. Pearson (Eds.) Trade and Market in the Early Empires. Economies in History and Theory. New York, Collier Macmillan: 270-307.

JANSSEN, J.

1994 Debts and Credits in New Kingdom. Journal of Egyptian Archaeology, 80: 129-136.

KEMP,B.

1972 Temple and Town in Ancient Egypt. In: P. Ucko, P.; R. Tringham; G. Dimbleby, Man, Settlemnt and Urbanism. London, Duckworth: 657-680

NORDSTRÖM, H.-A.

1972 Neolitic and A Group Sites. The Scandinavian Joint Expedition to Sudanese Nubia, Vol.3.

O’CONNOR, D. Copenhagen: Scandinavian University Books.

1989 City and Palace in New Kingdom Egypt. Cahier de Recherches de l'Institut de Papyrologie et d'Égyptologie de Lille, 11: 73-87.

1990 Urbanism in bronze Age Egypt and Northeast Africa. P. Robertshaw (Ed.) A History of African Archaeology. London, Portsmouth: 570-586. 
PELLINI, J.R. O uso do GIS para entender o sistema de trocas no Egito Antigo e na Núbia: mapas de circulação, uma nova abordagem para as superfícies de custo. Rev. do Museu de Arqueologia e Etnologia, São Paulo, 15-16: 209-245, 2005-2006.

\author{
OLSSON, G. \\ 1965 Distance and Human Interaction. A Review \\ and Bibliography. Regional Science Research \\ Institut, Pensylvania. \\ PELLINI, J.R. \\ 2005 Arqueologia espacial e as esferas de troca: \\ Um estudo do sistema econômico egípcio \\ durante o Novo Império. Tese de Doutorado. \\ São Paulo, Museu de Arqueologia e Etnologia \\ da Universidade de São Paulo. \\ RENFREW, C. \\ 1982 Alternative Models for Exchange and Spatial \\ Distribution. T. Earle; J. Ericson (Eds.) \\ Contexts for Prehistoric Exchange. New \\ York, Academic Press: 71-90. \\ SÄVE-SÖDERBERGH, T.; TROY, L. \\ 1990 New Kingdom Pharaonic Sites. The Finds
}

Recebido para publicação em 7 de março de 2006. and the Sites. The Scandinavian Joint Expedition to Sudanese Nubia, Vol.5: 2. Copenhagen: Scandinavian University Books.

SMITH, $\mathrm{H}$.

1976 The Fortress of Buhen: The Inscriptions. Egypt Exploration Society, Memoir 48.

\section{WILLIAMS, B.} London: Egypt Exploration Society.

1975 Archaeology and Historical Problems of the Second Intermediate Period. Ph.D. dissertation. Chicago, The University of Chicago.

1992 New Kingdom Remains from Cemeteries R, V, $S$ and $W$ at Qustul and Cemetery K at Adindan. The Oriental Institute Nubian Expedition, Vol. 6. Chicago: The Oriental Institute. 